\title{
Linking shifts in bacterial community with changes in dissolved organic matter pool in a tropical lake
}

\section{Avila, Marcelo P.}

2019-07-01

Avila , M P , Brandao , L P M , Brighenti , L S , Tonetta , D , Reis , M P , Staehr , P A , Asmala , E , Amado , A M , Barbosa , F A R , Bezerra-Neto , J F \& Nascimento , A M A 2019

, ' Linking shifts in bacterial community with changes in dissolved organic matter pool in a tropical lake ' , The Science of the Total Environment, vol. 672 , pp. 990-1003 . https://doi.org/10.1016/j.scitotenv.20

http://hdl.handle.net/10138/328897

https://doi.org/10.1016/j.scitotenv.2019.04.033

cc_by_nc_nd

acceptedVersion

Downloaded from Helda, University of Helsinki institutional repository.

This is an electronic reprint of the original article.

This reprint may differ from the original in pagination and typographic detail.

Please cite the original version. 
$1 \quad$ Linking shifts in bacterial community with changes in dissolved organic matter pool in

2 a tropical lake

3

4 Marcelo P. Ávila ${ }^{1}$, Luciana P. M. Brandão ${ }^{1}$, Ludmila S. Brighenti ${ }^{1}$, Denise Tonetta ${ }^{1}$, Mariana

5 P. Reis ${ }^{1}$, Peter A. Staehr ${ }^{2}$, Eero Asmala ${ }^{2,3}$, André M. Amado ${ }^{4}$, Francisco A. R. Barbosa ${ }^{1}$, José

6 F. Bezerra-Neto ${ }^{1}$, Andréa M. A. Nascimento ${ }^{1 *}$

7

$8{ }^{1}$ Departamento de Biologia Geral, Instituto de Ciências Biológicas, Universidade Federal de 9 Minas Gerais, Belo Horizonte, MG 31270-901, Brazil

$10{ }^{2}$ Department of Bioscience, Aarhus University, Frederiksborgvej 399, Box 358, 4000

11 Roskilde, Denmark

12 Tvärminne Zoological Station, University of Helsinki, J.A. Palménin tie 260, 10900 Hanko,

13 Finland

${ }^{4}$ Limnology Laboratory, Department of Oceanography and Limnology, Universidade Federal do Rio Grande do Norte, Rio Grande do Norte, Brazil,

*Corresponding author: Andréa M. A. Nascimento. Institutional address: Avenida Antônio 
27 Bacterioplankton communities have a pivotal role in the global carbon cycle. Still the interaction between microbial community and dissolved organic matter (DOM) in freshwater ecosystems remains poorly understood. Here, we report results from a 12-day mesocosm study performed in the epilimnion of a tropical lake, in which inorganic nutrients and allochthonous DOM were supplemented under full light and shading. Although the production of autochthonous DOM triggered by nutrient addition was the dominant driver of changes in bacterial community structure, temporal covariations between DOM optical proxies and bacterial community structure revealed a strong influence of community shifts on DOM fate. Community shifts were coupled to a successional stepwise alteration of the DOM pool, with different fractions being selectively consumed by specific taxa. Typical freshwater clades as Limnohabitans and Sporichthyaceae were associated with consumption of low molecular weight carbon, whereas Gammaproteobacteria and Flavobacteria utilized higher molecular weight carbon, indicating differences in DOM preference among clades. Importantly, Verrucomicrobiaceae were important in the turnover of freshly produced autochthonous DOM, ultimately affecting light availability and dissolved organic carbon concentrations. Our findings suggest that taxonomically defined bacterial assemblages play definite roles when influencing DOM fate, either by changing specific fractions of the DOM pool or by regulating light availability and DOC levels.

\section{Keywords:}

Community structure, bacterioplankton, CDOM, mesocosm, Verrucomicrobiaceae 
Introduction

50

Bacteria are key components of aquatic ecosystems playing crucial roles in

biogeochemical cycles and ecosystem functioning (Lindeman, 1942; Pernthaler, 2005). Due to their metabolic diversity, morphology, large biomass, and high turnover rates, bacteria respond quickly to changes in catchments and associated water, affecting carbon cycling and energy transfer to higher levels in aquatic food webs (Cotner and Biddanda, 2002; Sanders et al., 2015). Freshwater ecosystems are exposed to a variety of stressors related to anthropogenic activities like elevated nutrient inputs and increases in organic matter runoff (Carpenter et al., 2011). Associated with such impacts are changes in rates of aquatic primary production and respiration, and alterations in the overall flux of carbon and composition of dissolved organic matter (DOM) (Bocaniov et al., 2013; Brandão et al., 2018). Despite differences in molecular size and degradability (Hansen et al., 2016), both autochthonous and allochthonous DOM fuel bacterial metabolism, affecting the availability of inorganic nutrients and organic carbon ultimately determining if autotrophic or heterotrophic energy mobilization will prevail (Jansson et al., 2007; Berglund et al., 2007).

The autochthonous DOM mainly consists of simple molecules (carbohydrates, proteins and amino acids) of low molecular weight (LMW) and is typically more labile for microbial community (Farjalla et al., 2009; Fonte et al., 2013). On the other hand, the allochthonous DOM is more susceptible to photodegradation because it contains relatively large molecules with high numbers of aromatic compounds, which strongly absorb UV light (Amon and Benner, 1994; McKnight et al., 1994; Benner, 2002; Helms et al., 2008). In this context, the chromophoric fraction of DOM (CDOM) constitutes an important and very variable pool of carbon, consisting of a continuum from labile to recalcitrant constituents (Rochelle-Newall et al., 2004, Benner and Amon, 2015). Bacterioplankton can increase the 
amount of CDOM by transforming non-colored autochthonous DOM (Nelson et al., 2004;

Asmala et al., 2018). Previous studies show that BCS varies with DOM composition and suggest ecological coherence between BCS and DOM composition (Judd et al., 2006; Amaral et al., 2016; Sarmento et al., 2016). While community adaption (i.e. composition shifts) has been found to precede bacterial degradation of specific carbon substrates (Cory and Kling, 2018), the contribution of BCS shifts and key bacterial players in the production and degradation of CDOM is unclear (Zhang et al., 2018).

Spectrophotometric analysis of CDOM is an important tool in studies of composition and origin of organic matter (Helms et al., 2008; Massicotte et al., 2017). Metrics extracted from the CDOM absorbance spectrum provide information on aromaticity (SUVA 254 ; Weishaar et al., 2003), changes in relation to photo- $\left(\mathrm{S}_{275-295}\right)$ and biodegradation $\left(\mathrm{S}_{350-400}\right)$ (Helms et al., 2008), and changes in the relative size of DOM molecules $\left(\mathrm{a}_{250}\right.$ : $\mathrm{a}_{365}$; De Haan and De Boer, 1987). Brandão et al. (2018) similarly used DOM optical proxies to infer a range of quantitative and qualitative changes observed during a factorial mesocosm experiment employing additions of allochthonous DOM and inorganic nutrients. Their results indicated that additions of allochthonous DOM affected CDOM absorption in the PAR range, with high influence of photodegradation. In contrast, more labile autochthonous DOM was degraded by bacteria, as suggested by Berggren et al. (2009).

Here, we applied a high-resolution taxonomic community analysis to characterize changes in the bacterioplankton and link this to the dynamics of the DOM pool documented by Brandão et al. (2018). By relating our findings to the DOM optical proxies described above, and results from the same mesocosm experiment (Tonetta et al., 2018; Brighenti et al., 2018), we aimed to provide insights on the interaction between DOM and BCS. By tracking down taxonomic signatures associated with specific changes in DOM, we expect a high degree of resource partitioning among bacterioplankton, as previously suggested for marine 
waters (McCarren et al., 2010; Sarmento et al., 2016). This presumption is endorsed by the great bacterioplankton diversity previously observed in the studied lake (Ávila et al., 2017). Additionally, the effect of direct and reduced sunlight was considered to investigate how photodegradation affects the association between BCS and DOM properties.

\section{Methods}

\section{Study area}

The data from this study originates from the mesocosm experiment described in detail by Brandão et al. (2018). In summary, the experiment was carried out in Lake Carioca $\left(19^{\circ} 45^{\prime} 26.0^{\prime}\right.$ 'S ; 42 $37^{\prime} 06.2^{\prime}$ 'W) located in the Rio Doce State Park, a remnant protected area of the Atlantic Forest (Minas Gerais, Brazil). This conservation unity is of great importance for global maintenance of biological diversity (http://www.ramsar.org). Lake Carioca is a small (perimeter: $1,718 \mathrm{~m}$, area: $0.14 \mathrm{~km}^{2}$, volume: $671 \times 10^{3} \mathrm{~m}^{3}$, maximum depth: $11.8 \mathrm{~m}$, mean depth: 4.8 m; Bezerra-Neto et al., 2010), turbid, mesotrophic and monomictic lake. The experiment was carried out in January, when Lake Carioca waters are found to be stratified (from September to April), increasing the lake euphotic zone depth and water transparency (Barbosa et al., 2012). Further characteristics of Lake Carioca can be found elsewhere (Brighenti et al., 2015; Reis et al., 2016).

\section{Mesocosm setup and water physico-chemical characterization}

The experiment was planned to mimic seasonal changes in inputs of allochthonous DOM and nutrients associated with variability in rain, water level and litter fall. It was carried out during summer 2015 (20 $0^{\text {th }}$ January to $1^{\text {th }}$ February). Mesocosms (1.5 m height, 1.3 m diameter and volume $2 \mathrm{~m}^{3}$ ) were installed in the upper mixed zone of the lake. The experiment applied a $2^{3}$ factorial design with different combinations of inorganic nutrients 
and allochthonous DOM additions and shading in two replicates each, totalizing 16

mesocosms (Fig. S2). Each mesocosm was named according to the allochthonous DOM (C), inorganic nutrient $(\mathrm{N})$, and light $(\mathrm{L})$ in that particular order (e.g., additions of allochthonous DOM and nutrient under shading: $\mathrm{C}^{+} \mathrm{N}^{+} \mathrm{L}^{-}$). Inorganic nutrient additions consisted of initial inoculation with nitrate $\left(6.1 \mathrm{~g}\right.$ of $\left.\mathrm{NaNO}_{3}\right)$, ammonium $\left(0.42 \mathrm{~g}\right.$ of $\left.\mathrm{NH}_{4} \mathrm{Cl}\right)$ and phosphate $(1.15$ $\mathrm{g}$ of $\mathrm{K}_{2} \mathrm{HPO}_{4}$ ) diluted in $40 \mathrm{ml}$ of distilled water, resulting in initial concentrations of 2,575 $\mu \mathrm{g} \mathrm{NO}_{3}{ }^{-} \mathrm{L}^{-1}, \quad 71 \mu \mathrm{g} \mathrm{NH}_{4}{ }^{+} \mathrm{L}^{-1}$ and $160 \mu \mathrm{gO}_{4}{ }^{-3} \mathrm{~L}^{-1}$ at the amended bags. The allochthonous DOM consisted of fallen leaves, plant detritus and soil particles collected from forest floor bordering Lake Carioca. The litter material was dark-incubated for seven days at room temperature $\left(32^{\circ} \mathrm{C}\right)$ in buckets filled with $60 \mathrm{~L}$ of distilled water without nutrient supplementation. Following, the admixture was filtered on a $62 \mu \mathrm{m}$ mesh and $7.5 \mathrm{~L}$ of the filtrate were added in $\mathrm{C}^{+}$treatments, resulting in an initial concentration of $8.6 \mathrm{mg} \mathrm{DOC} \mathrm{L}^{-1}$. To study the influence of the light availability in the mesocosms a shade net was placed reducing $50 \%$ of light irradiance. The efficacy of light attenuation was confirmed using a radiometer BIC (Biospherical Instruments, United States of America). The DOM proxies assessed were absorbance at $350 \mathrm{~nm}\left(\mathrm{a}_{350}\right)$, spectral slopes between $275-295 \mathrm{~nm}\left(\mathrm{~S}_{275-295}\right)$ and $350-400 \mathrm{~nm}\left(\mathrm{~S}_{350-400}\right)$, DOC and its normalized absorbance at $254 \mathrm{~nm}$ (SUVA) and diffuse PAR attenuation coefficient $\left(\mathrm{K}_{\mathrm{dPAR}}\right)$. $\mathrm{a}_{350}$ is a quantitative proxy of photo-absorbing DOM (De Haan and De Boer, 1987), $\mathrm{S}_{275-295}$ and $\mathrm{S}_{350-400}$ are qualitative indicators of photo- and biodegradable CDOM, respectively, and values are inversely proportional to CDOM molecular weight (Helms et al., 2008). SUVA indicates DOM aromaticity (Weishaar et al., 2003) and $\mathrm{K}_{\mathrm{dPAR}}$ is inversely proportional to the availability of light in the PAR range (Kirk 1994), being both quantitative and qualitative proxies. All measurements and calculations were made as described by Brandão et al. (2018), except for $K_{\mathrm{dPAR}}$ (Brandão et al., 2016). 
Detailed information on the experimental design and measurements are described by Brighenti et al. (2018) and Tonetta et al. (2018).

\section{Sample collection}

Water samples $(250 \mathrm{ml})$ from all 16 mesocosms were taken on days 1, 2, 3, 6, 9 and 12 , whereas on day 0 only the control $\left(\mathrm{C}^{-}\right)$and allochthonous DOM added $\left(\mathrm{C}^{+}\right)$mesocosms were sampled, as nutrient was added aseptically. Thus, we considered that initial differences in microbial communities were limited to microbes inoculated via allochthonous DOM addition. Samples were immediately transported to the laboratory, filtered $(0.22 \mu \mathrm{m}$, Millipore, Billerica, MA, USA) and stored at $-20^{\circ} \mathrm{C}$ until DNA extraction.

\section{DNA extraction, library construction, sequencing and qPCR}

Total DNA was extracted using the E.Z.N.A. ® Soil DNA Kit (OmegaBio-Tek) as recommended by the manufacturer and quantified with the Qubit fluorometer (InvitrogenLife Technologies, USA). Following DNA isolation, paired-end libraries were constructed to assess the bacterial community composition using the primers S-D-Bact-0341-b-S-17/S-DBact-0785-a-A-21 (Klindworth et al., 2013), with Illumina adapters added, which target the V3-V4 regions of the 16S rRNA gene. The paired-end sequencing of the libraries was performed in an Illumina MiSeq platform (San Diego, CA, USA).

In order to assess the bacterial abundance, the $16 \mathrm{~S}$ rRNA gene was estimated using the primer set 338F (5'TACGGGAGGCAGCAG3') (Lane et al., 1991) and 518R (5'ATTACCGCGGCTGCTGG3') (Muyzer et al., 1993), and the ABI 7900HT Fast RealTime PCR System. (Applied Biosystems, Foster City, CA). Reaction conditions were as described by Reis et al. (2013). 


\section{Bioinformatics}

After sequencing, raw reads were merged and processed using MOTHUR v.1.34.4 (Schloss et al., 2009), including quality filtering (length $<400$ and $>430$, without ambiguities and homopolymers > 8), chimera check and singleton exclusion using UCHIME (Edgar et al., 2011). The remaining reads were aligned and classified against the SILVA v.123 database (Quast et al., 2013) and clustered into operational taxonomic units (OTUs) using 3\% as dissimilarity cutoff. Reads not classified into the Bacteria domain were removed (3 reads, representing $<10^{5} \%$ of total).

\section{Data analysis}

All statistical analyses were performed in R (https://www.r-project.org - R Core Team 2018) and the main steps performed are summarized in Figure S3. For alpha and beta diversity (PCoA) analyses reads assigned as Cyanobacteria and chloroplasts were removed from the dataset. Alpha diversity metrics (OTU richness and Simpson Evenness index) were determined after random normalization of reads counts at 1,629 reads depth. Changes in $16 \mathrm{~S}$ abundance measures, alpha and beta diversity (described below), and DOM proxies were assessed using multiple linear regression analysis considering time, allochthonous DOM and nutrient additions and shade as explanatory variables, contemplating also first-order interactions. In order to evaluate regular time intervals and adjust community data to the same sampling frequency of DOM-related data, only samples from days $0,3,6,9$ and 12 were considered. The percentages of Cyanobacteria and chloroplasts, which are derived from eukaryotic phototrophs, were calculated using the sum of the relative frequency of all reads classified as members of these groups, the remaining reads were assumed to represent bacterioplankton. 

samples with more than 2,000 reads (3 out of 99 samples were removed: $\mathrm{C}^{-} \mathrm{N}^{+} \mathrm{L}^{+}$day 12 , $\mathrm{C}^{+} \mathrm{N}^{-} \mathrm{L}^{+}$day 3 and $\mathrm{C}^{+} \mathrm{N}^{+} \mathrm{L}^{-}$day 9). After pruning these samples, a mean sample size of 57,562 reads was observed. The normalization of reads per sample was based on cumulative sum scaling, as implemented by metagenomeSeq (Paulson et al., 2013), which conserves the relative proportion of species. Normalized OTU counts were further squared-root transformed and dissimilarity was calculated using weighted UniFrac distances (Lozupone et al., 2005) using the R-package phyloseq (McMurdie and Holmes, 2013). The input tree used for UniFrac distance calculation was generated in MOTHUR with the clearcut program (Evans et al., 2006), using the most abundant representative sequence of each OTU. The sample and OTU scores of the first three principal coordinates were subsequently extracted. The same procedure used to model the environmental variables was used to evaluate the relationship between the sample scores (response variable) and time, allochthonous DOM and nutrient additions and shade (explanatory variables).

To evaluate the synchronism in changes of DOM and BCS, a causality diagram was created to compare the outcomes from switching DOM proxies and principal coordinates extracted from the PCoA as factor and determinant on each other. Hence, it was tested whether temporal shifts in one type of variable $(\triangle \mathrm{PCoA}$ or $\triangle \mathrm{DOM})$ were correlated with preceding $\left(\mathrm{PCoA}^{\text {initital }}\right.$ or $\left.\mathrm{DOM}^{\text {initial }}\right)$ or subsequent $\left(\mathrm{PCoA}^{\text {final }}\right.$ or $\left.\mathrm{DOM}^{\mathrm{final}}\right)$ levels of the other type of variable. Correlations likely indicate synchrony and were used to reveal positive and negative stimuli between community gradients (PCoA axis) and DOM proxies. This was done by comparing all possible combinations of linear regressions tested between DOM proxies and scores of the three main PCoA's axes: changes within a three-day interval in one hand $\left(\triangle \mathrm{PCo} \mathrm{A}^{0-3}\right.$ and $\triangle \mathrm{DOM}^{0-3}$ - response variable) versus either levels of the explanatory variable immediately before $\left(\mathrm{PCoA}^{0}\right.$ and $\left.\mathrm{DOM}^{0}\right)$, or after $\left(\mathrm{PCoA}^{3}\right.$ and $\left.\mathrm{DOM}^{3}\right)$ the three-day 
shift. Resultant significant linear regressions $(p$-value $<0.05)$ exhibiting a coefficient of determination $\left(R^{2}\right)>0.2$ were further considered and summarized in the causality diagram. The time interval of three days was chosen based on results from an experiment performed during field campaign in which carbon lability was inferred from daily changes of $\mathrm{pCO}_{2}$ levels in dark incubations at $30^{\circ} \mathrm{C}$, similar to lake conditions. Within three days, all treatments except one $\left(\mathrm{C}^{+} \mathrm{N}^{+} \mathrm{L}^{+}\right)$had achieved maximum carbon remineralization, as $\mathrm{pCO}_{2}$ reached the highest values, decreasing afterwards (Fig. S4).

To identify the taxonomic groups associated with each PCoA axis, the dispersion of OTU scores was inspected at different taxonomic levels. Plots were made to show the most abundant taxa considering pre-determined cut-offs of OTU richness per hierarchy, as follow 30, 25, 15 and 10 for phylum, class, family and genus, respectively. An additional selection for a class final plot considered the five highest and lowest mean scores presented by taxon for all PCoA axes, whereas for family and genus, the eight highest and lowest mean scores were selected for each axis. Plots were drawn using the geom_violin function in the ggplot2 package (Wickham et al., 2016), a feasible way to incorporate the density (i.e., indicating number of OTUs) along axis scores, thus illustrating the PCoA axis scores interval which a given taxon displays increased OTU richness. Finally, in order to reduce the number of taxa displayed and depict the distribution of OTUs over the three PCoA axis in an easily comparable fashion, trilinear plots were built using the function ggtern (Hamilton and Ferry, 2018). The taxa chosen for the plots represented the 12 (phylum and class) and 16 (family and genus) bacterial groups, which better illustrated the different occurrence patterns observed for each hierarchic level. Each plot shows all OTUs of a given taxonomy in relation to their normalized PCoA species scores: PCoA1 + PCoA2 + PCoA3 = $1(100 \%)$. Colored areas represent the OTUs distribution density according to a Gaussian kernel estimator implemented in the stat_density_tern function in ggtern. 
All sequences were submitted to the Sequence Read Archive

247 (http://www.ncbi.nlm.nih.gov/sra/) under the BioProject ID PRJNA515842.

248

Results

250

251

\section{Changes in microbial characteristics and DOM-related proxies}

252

The effect of shading and additions of nutrient and allochthonous DOM on microbial aspects (i.e. 16S abundance, richness, evenness and relative abundance of heterotrophs and phototrophs) of the mesocosms are shown in Figure 1 and Table 1. We did not observe influence of light in microbial measurements $(\mathrm{p}>0.05) . \mathrm{C}^{+}$and $\mathrm{N}^{+}$mesocosms presented similar increases in $16 \mathrm{~S}$ mean abundance (331.0 and $291.1 \%$, respectively). Community richness was higher in $\mathrm{C}^{+}$mesocosms (25.5\%), particularly at the beginning of the experiment due to the inoculation of allochthonous DOM-associated microbes. However, a reduction over time (-1.9\% per day) was observed, thereby neutralizing the initial enrichment. Bacterioplankton relative abundance and community evenness diminished in $\mathrm{N}^{+}$treatments over time (-2.9\% and $-3.1 \%$ per day, respectively), with strongest effects on bacterioplankton relative abundance. The relative abundance of Cyanobacteria was reduced by allochthonous DOM addition ( $-5.8 \%$ per day) and increased by nutrient addition (5.3\% per day). The relative abundance of chloroplasts was also reduced in treatment $\mathrm{C}^{+}(-86.0 \%)$ and increased in $\mathrm{N}^{+}(65.3 \%)$ considering total changes, however both additions caused daily increases of 18.0 and $8.4 \%$, respectively.

Differently from microbial parameters, changes in DOM optical properties to manipulations were overall stronger and significant for all treatments, including shading (Fig. 
$271(56.5 \%)$ proxies. Nutrient addition increased $\mathrm{a}_{350}(9.1 \%)$ and decreased $\mathrm{S}_{275-295}(-2.2 \%)$,

272 meanwhile shading contributed for a reduction of $\mathrm{S}_{275-295}\left(-0.3 \%\right.$ per day), $\mathrm{S}_{350-400}(-1.1 \%)$

273 and increase in $\mathrm{a}_{350}\left(9.1 \%\right.$ in $\mathrm{N}^{-}$treatments, only).

\section{Bacterioplankton community structure}

Changes in BCS, assessed through a PCoA, showed that nutrient and allochthonous

277 DOM additions affected community structure differently, while the effect of shading was

inconclusive (Fig. 3). Allochthonous DOM addition promoted changes in BCS on day zero.

This effect seems to have persisted in absence of nutrient supplementation, as the dissimilarity between $\mathrm{N}^{-} \mathrm{C}^{+}$and $\mathrm{N}^{-} \mathrm{C}^{-}$treatments was observed throughout the experiment. In contrast, pronounced changes observed in $\mathrm{N}^{+}$treatments over time resulted in more similar communities, despite the allochthonous DOM addition. Between days 6 and 12, the $\mathrm{N}^{+}$ communities experienced notable changes, segregating from $\mathrm{N}^{-}$communities towards high PCoA1 and 2 scores.

The three main principal coordinates accounted for $57.5 \%$ of community variation (Fig. S5 and Table 3). PCoA1 was mainly influenced by the interaction between time and nutrient addition, increasing with a daily rate of $42.4 \%$. A minor gain over time was also caused by allochthonous DOM addition (11.7\% per day), as well as by time alone (10.5\% per day). PCoA2 had a complex pattern of variance, mainly influenced by allochthonous DOM and nutrient additions. Initially, axis 2 was augmented in $\mathrm{C}^{+}$treatments, however, as the scores suddenly decreased until day three, the overall effect of allochthonous DOM addition was weak and non-significant. Moreover, scores tended to diminish over time $(-7.3 \%$ per day), except for $\mathrm{N}^{+}$treatments, which increased at a daily rate of $9.2 \%$. Differently from the other axes, in which a large score variation occurred during initial (PCoA2) or late (PCoA1 and 2) periods, PCoA3 exhibited a pattern of variance defined by a scores' peak occurring on 
day 3 and a second peak close to day 12. Although the effect of allochthonous DOM addition was not significant, the highest peak of PCoA3 scores was achieved in treatment $\mathrm{C}^{+} \mathrm{N}^{+}$, reflecting a further stimulation by allochthonous DOM addition.

\section{Linking DOM proxies and changes in BCS}

The assessment of synchrony in changes of the carbon pool and BCS suggested that the influence of BCS on DOM fate (Table 4, $\triangle \mathrm{PCoA}^{0-3} \sim \mathrm{DOM}^{3}$ and $\Delta \mathrm{DOM}^{0-3} \sim \mathrm{PCoA}^{0}$ ) was stronger than microbial adaptation in response to DOM (Table 5, $\triangle \mathrm{PCoA}^{0-3} \sim \mathrm{DOM}^{0}$ and $\left.\Delta \mathrm{DOM}^{0-3} \sim \mathrm{PCoA}^{3}\right)$. Whereas quantitative DOM proxies as DOC and $\mathrm{K}_{\mathrm{dPAR}}$ were both associated with PCoA1 and 3, qualitative proxies such as $\mathrm{S}_{350-400}$ were linked to PCoA2 and 3, suggesting a disjuncture in the relationship between DOM and BCS (Tables 4 and 5). The optical proxies $\mathrm{a}_{350}$, SUVA (both associated with PCoA3) and $\mathrm{S}_{275-295}$ (PCoA2) correlated to one principal coordinate each, indicating constricted associations with the bacterioplankton community. Therefore, PCoA1 was related to quantitative and PCoA2 was related to qualitative measures of DOM, while PCoA3 was related to both qualitative and quantitative proxies. Moreover, PCoA3 yielded stronger correlations with a larger number of proxies than the two other axes, likely representing a community fraction highly committed with DOM variation.

Figure 4 illustrates positive and negative associations between BCS and DOM-related proxies, as well as the effect of shading on these interactions. The spectral slopes were

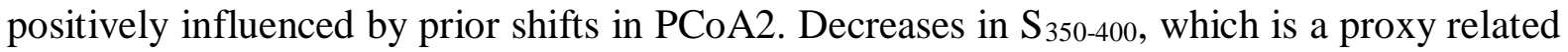
to biodegradable DOM, and increases in CDOM (a 350$)$ anticipated high PCoA3 scores. The influences of PCoA2 on $\mathrm{S}_{350-400}\left(R^{2}=0.46\right.$ and $\left.p=0.003\right)$ and of $\mathrm{S}_{350-400}\left(R^{2}=0.37\right.$ and $\left.p=0.002\right)$ and $\mathrm{a}_{350}\left(R^{2}=0.27\right.$ and $\left.p=0.01\right)$ on PCoA3 were more predictable under shading (Figs. S6 and S7). PCoA3 was the major regulator of DOM-associated properties, affecting also DOM 
aromaticity (SUVA) and quantity (DOC). The reason why the relationship between DOC levels and PCoA3 seemed dubious (Fig. 4), may be the pulse-like variation of PCoA3 scores over time (Fig. S5). Across the time series, PCoA3 peaks coincided with minimum DOC levels in most treatments (Fig. 2). Likewise, while high DOC levels anticipated gain of PCoA3 scores, increasing PCoA3 resulted in subsequent low DOC levels. Thus, the DOC increase observed after high PCoA3 scores was a consequence of the recovery of DOC levels posterior to high abundances of high-PCoA3 bacteria. Therefore, our results indicate that PCoA3 pulses were DOC-consuming events followed by low abundance of high-PCoA3 bacteria, which lasted until newly synthetized DOC joined the DOM pool. Increases in PCoA1 scores contributed to restore DOC levels, especially without shading $\left(R^{2}=0.39\right.$ and $p=0.001$, Fig. S8). Moreover, PCoA3 was also associated with the availability of light for photosynthesis $\left(\mathrm{K}_{\mathrm{dPAR}}\right)$, which has impacted PCoA1.

\section{Taxonomic assignment}

Figures 5 to 8 illustrate how the OTU richness of different bacterial groups changed in response to the main community drivers, as estimated by the first three PCoA axes. By evaluating the constraining effect of PCoA scores on taxa richness, we expected to obtain information on taxonomic adaptability in face of the observed changes in DOM pool. The dispersion of taxa richness over PCoA scores varied widely according to taxonomic level. As occurrence (Figs. S10 to S13). the four more abundant phyla, Actinobacteria and Verrucomicrobia were in line with this pattern, meanwhile among Proteobacteria and Bacteroidetes more OTUs with increased 
346 PCoA1 were observed, suggesting enrichment at the final experimental days, especially in $\mathrm{N}^{+}$ 347 treatment (Fig. S10). At the class level, OTUs belonging to Alphaproteobacteria and 348 Cytophagia achieved higher PCoA1 scores, whereas other classes like Spartobacteria, 349 Acidimicrobiia and Clostridia were constrained to low scores (Fig. 6). Considering the 350 observed association between PCoA1 and the proxies DOC and $\mathrm{K}_{\mathrm{dPAR}}$, taxa exhibiting high 351 PCoA1 scores as Cytophagia are likely associated with active DOC production under increased availability of light at the PAR range. This distribution pattern was observed for OTUs associated with the family Rhodobacteraceae (Fig. 6) and the genus Tabrizicola (Fig. 8). Increases in DOC levels, water clarity (low $\mathrm{K}_{\mathrm{dPAR}}$ ) (Fig. 4), density of plastid-associated producers, and $\mathrm{pH}$ were all positively associated with PCoA1 (Fig. S14). As some of these associations were more predictable under full light (Figs. S8 and S15), an increase in $\mathrm{CO}_{2}$ availability due to photo-oxidation might have contributed to the enhancement of productivity (as discussed by Tonetta et al., 2018), consequently favoring high-PCoA1 groups. Moreover, as the strongest declines in DOC levels occurred after rather than simultaneously to PCoA1 increases (Fig S16), the observed reduction in DOC levels was likely a consequence of DOM degradation by bacterial lineages exhibiting a pulse-like occurrence, like high-PCoA3 bacteria. Therefore, the associations between PCoA1 and the DOM pool resulted from the phytoplankton-associated production of autochthonous carbon rather than from a bacterioplankton-regulated process.

Axis 2 scores were low or intermediate for the dominant phyla. Actinobacteria (specially the Actinobacteria class) and Chloroflexi were remarkably enriched at low PCoA2 scores, suggesting that these phyla exhibited preferences for late non-supplemented conditions (Figs. 5 and 6). In contrast, Firmicutes (except for Bacilli class) was markedly enriched at high PCoA2 scores found at $\mathrm{C}^{+}$treatment on the initial stage of the experiment, thereby implying an association with allochthonous DOM input. Such OTU distribution 
pattern was exhibited by the families Veillonellaceae, Ruminococcaceae and

372 Clostridiaceae_1 (Firmicutes), likewise Sphingobacteriaceae (Bacteroidetes) (Fig. 7).

373 Differently, three proteobacterial families (Oxalobacteraceae, Xanthomonadaceae and

374 Pseudomonadaceae) distinctly presented reduction of OTUs as PCoA2 decreased. Regarding

375 the PCoA2 association with qualitative CDOM proxies, these families were likely high

376 molecular weight (HMW) carbon consumers supporting increases in $\mathbf{S}_{275-295}$ and $\mathbf{S}_{350-400}$. In

377 contrast, most families presenting low PCoA2 as Sporichthyaceae, LD12, FukuN57 and

378 Saprospiraceae likely showed preferences for low molecular weight (LMW) carbon and

379 contributed to the reduction of the spectral slopes.

380 Like axis 1, most phyla exhibited low PCoA3 scores (Fig. 5). Notably, slightly increased scores were detected for Verrucomicrobia and Planctomycetes. Taxa showing increased PCoA3 scores as the Verrucomicrobial families Verrucomicrobiaceae and P. palm_C85 were likely involved in the PCoA3 peaks occurring on days 3 and 12 (Fig. 7). As assumed from the associations between PCoA3 and the DOM proxies, these taxa seem to play a role in CDOM consumption, reducing DOC levels and light attenuation in the PAR range. The regulation of DOC changes by bacteria linked with PCoA3 was stronger in nutrient supplemented treatments (Fig. S17). Verrucomicrobia Prosthecobacter, Haloferula and Luteolibacter were among genera that reached the highest PCoA3 values (Fig. 8), likely being typical representatives of this recycling lifestyle.

\section{Discussion}

Despite many previous studies have reported changes in BCS in response to DOM composition (Kritzberg et al., 2006; Judd et al., 2006; Gomez-Consarnau et al., 2012; Roiha et al., 2016; Smith et al., 2018), evidences for BCS influencing DOM characteristics are scarce (Guerrero-Feijóo et al., 2017; Goldberg et al., 2017; Wu et al., 2018). Our results 
provide insights on links between observed changes in BCS and in the carbon pool, with 397 community composition influencing and responding to specific DOM properties. Importantly, there was a strong influence of BCS on DOM processing and transformation, indicating that as some bacterial components use different substrates, they alter the DOM 400 pool in specific ways. We also found that nutrients input was the main driver of bacterioplankton community and activity, either by enhancing microbial growth rates or through phytoplankton-DOM production, consistent with previous studies (Osterholz et al., 2016; Landa et al., 2016). Notably, our findings indicate that specific microbial members have potential impacts on changes in DOM pool molecular weight and suggest that a specific group, Verrucomicrobiaceae, plays a key role in CDOM turnover in these tropical waters.

\section{Primary production as a driver of bacterial community changes}

The most pronounced change in BCS (PCoA1) was caused by nutrient addition, which furthermore enhanced air-water fluxes of $\mathrm{CO}_{2}$ and $\mathrm{O}_{2}$ (Tonetta et al., 2018), pelagic metabolic rates (Brighenti et al., 2018) and autochthonous DOC levels (Brandão et al., 2018). Our results also showed that PCoA1 was a proxy of a nutrient-induced impoverishment of bacterial diversity (Figs. 5 to 8). During the experiment, the heterotrophic activity was likely constrained as soon as the initially available labile carbon was respired, which happened briefly under nutrient supplementation, as shown by the sudden decreases in $\mathrm{pCO}_{2}$ after the second day (Tonetta et al., 2018). In turn, simultaneous increases in PCoA1 scores, DOC levels, frequencies of Cyanobacteria and chloroplasts, together with decreases in bacterioplankton frequency and evenness were observed after day three in $\mathrm{N}^{+}$treatments, indicating that a "heterotrophic collapse" had occurred. In this sense, most taxa exhibiting low PCoA1 scores (Figs. 5 to 8 ) were likely outcompeted by phytoplankton and 419 phytoplankton-associated bacteria. In addition to the effects of DOM and nutrient additions 420 on BCS, pelagic community metabolism, including background bacterial respiration, were 
also greatly affected (Brighenti et al., 2018). This supports previous findings that the growth

422

423

424

425

426

427

rate of planktonic microorganisms is strongly depended on the availability of nutrients and labile DOM, favoring fewer and faster growing bacterial species rather than more diverse community under slower growth conditions (Sterner and Elser, 2002; Godwin and Cotner, 2014).

Our results indicate that the class-level OTU classification discriminates phytoplankton-associated and/or fast-growing bacteria from groups with either limited capacity to directly compete with phytoplankton, or incapable of thriving under high productivity (Fig. 6). The latter represent the lake epilimnetic background community, particularly enriched by Actinobacteria and Verrucomicrobia, which are abundant phyla in Lake Carioca (Ávila et al., 2017). Moreover, a decrease in community evenness over time was observed specially for $\mathrm{N}^{+}$treatments, indicating that a few lineages colonized during periods of high primary production (e.g. classes Alphaproteobacteria and Cytophagia). Members of Alphaproteobacteria, especially the Rhodobacteraceae family, and Cytophagia have been consistently associated with phytoplankton-derived DOM (Eckert et al., 2012; Sarmento et al., 2016; Bunse et al., 2016). Within these groups, genera associated with highPCoA1 scores, like Tabrizicola, have been found to be closely associated with phytoplankton in a symbiotic lifestyle (Cui et al., 2017), supporting a tight relation between high-PCoA1 faster-growing lineages and primary producers. Lineages reaching high-PCoA1 scores were likely supported by a carbon substrate that might not transform the DOM pool (Lucas et al., 2016). Accordingly, bacteria associated with PCoA1 seems to involve fast-growing bacteria capable of rapidly incorporating freshly produced phytoplankton exudates (Fouilland et al., 2014). Indeed, preference for high concentrations of phytoplankton-derived DOM is suggested by the positive link between PCoA1 and DOC levels (Fig. S8). Sarmento et al. (2016) have shown that members of Bacteroidetes, which in our study exhibited high PCoA1 
scores (classes Cytophagia and Flavobacteria), are more active with increasing

447 phytoplankton-DOM concentration.

\section{Changes in DOM quality and allochthonous DOM influence}

Shifts in BCS observed by the second principal component axis, PCoA2, were closely related to indices of DOM quality. Such shifts were initially influenced by allochthonous DOM addition, which induced notably high PCoA2 scores at day zero. However, nutrient addition also imposed a late increase in PCoA2 scores, suggesting that the influence of BCS on the qualitative DOM proxies $S_{350-400}$ and $S_{275-295}$ represent bacterial transformation of phytoplankton-produced and terrigenous carbon. These proxies are useful for tracking different pools of allochthonous and autochthonous DOM (Brandão et al., 2016). As $S_{350-400}$ and $\mathrm{S}_{275-295}$ both record changes in carbon molecular size (Helms et al., 2008), the enrichment of phyla exhibiting low PCoA2 scores, like Actinobacteria and Chloroflexi, likely contributed to the augment of DOM molecular weight. In contrast, reduction of DOM molecular weight resulted from the increased abundance of Saccharibacteria and Parcubacteria, which presented high-PCoA2. Importantly, full light seems to have hindered the effect of these BCS shifts on biodegradable DOM (Fig. S6), by blurring the association between changes in PCoA2-associated bacteria (especially LMW carbon consumers, as Sporichthyaceae, Saprospiraceae and FukuN57) and DOM quality. Oppositely, shading stimulated the bacterial groups competing for substrate with the photo-transformation processes, thereby stabilizing the influence of these taxa on DOM quality. Alternatively, an enhanced production of LMW autochthonous DOM was likely favored by reduced photoinhibition of phytoplankton in shaded treatments (Brighenti et al., 2018).

An alternative ecological interpretation of BCS shifts (here PCoA2), concerns the early stage of the experiment, when communities in $\mathrm{C}^{+}$treatments showed remarkable changes (Fig. S9). The inoculation of bacteria-containing allochthonous litter strongly 
affected $\mathrm{BCS}$ in $\mathrm{C}^{+}$treatments until day three, when all treatments exhibited very similar

472 PCoA2 scores. Allochthonous bacteria were represented mainly by fermentative taxa belonging to Firmicutes (e.g. Ruminoccocaceae and Veillonellaceae, Fig. 7) and other

474 lineages direct or indirectly associated with plant-polysaccharide degradation, as 475 Saccharibacteria and Mucilaginibacter (Figs. 5 and 8, respectively) (Pankratov et al., 2007;

476 Starr et al., 2018). Similarly to PCoA2 scores, OTU richness was immediately increased by 477 allochthonous DOM supplementation (Fig. 1) and then diminished, suggesting that PCoA2 also represented a strong selective pressure on allochthonous lineages in the lake. Therefore, genera highly abundant on $\mathrm{C}^{+}$treatments on day zero, like Sporomusa, had OTUs condensed at the higher limit of PCoA2 and were briefly cleared away, meanwhile Burkholderia has thriven later, exhibiting lower values of PCoA2, suggesting a short but higher persistency (Fig. 8). The rapid fading of inoculum-associated bacteria might have occurred due to high oxygen levels, which has probably constrained the occurrence of obligate anaerobes and microaerophiles within Clostridia and Negativicutes (Fig. 6) (Wiegel et al., 2006, Marchandin et al., 2010). In contrast, lineages as Burkholderia, which were also initially favoured by allochthonous DOM addition but resisted longer, were possibly benefited by its ability to tolerate oxidative stress conditions and to thrive in association with photodegraded organic matter (Paul et al., 2012). In comparison, the family level was more suitable than genus for detecting gradual and homogeneous changes throughout PCoA2 scores, thus allowing the recognition of taxa consistently contributing to the observed changes in DOM quality. As an example, increased richness of Sporichthyaceae and FukuN57 occurred downwards PCoA2 scores (Fig. 7). These taxa, together with the genera Limnohabitans and of LMW carbon (Jones et al., 2009; Šimek et al., 2010; Eckert et al., 2012). In contrast, usually assumed as copiotrophic microbes (Nelson and Carlson, 2012; Landa et al., 2013), 
gammaproteobacteria (families Xanthomonadaceae and Pseudomonadaceae) and

497 Flavobacteriaceae presented enrichment at increasing PCoA2 scores, suggesting preference

498

499

500

501

502

503

504

505

506

507

508

509

510

511

512

513

514

515

516

517

518

519

520 for HMW DOM as also previously suggested by Amaral et al. (2016) and Orsi et al. (2016). Importantly, Zhang et al. (2015) has shown that in oceanic waters, these groups are involved in the degradation of HMW exopolysaccharides potentially resulting in production of humiclike recalcitrant DOC, especially in replete $\mathrm{N}$ and $\mathrm{P}$ conditions. This could explain the association between high PCoA2 scores and increases in SUVA observed under nutrient supplementation (between days 0-3 and 9-12, Fig. 2), suggesting a participation of highPCoA2 lineages in DOM aromatization. Therefore, as shifts in BCS as described above occur, they seem to affect and shape the DOM pool by depleting substrates of distinct molecular weight, thus contributing to changes in spectral slopes and overall DOM quality.

\section{CDOM recycling}

The third principal component axis (PCoA3) was a component of the bacterioplankton community highly committed to the observed changes in DOM pool (Fig. 4). Increases in PCoA3 scores resulted in lower DOC levels, which were subsequently recovered after the PCoA3 pulse (Table 4). The regulation of DOC changes by bacteria linked with PCoA3 were more robust in nutrient supplemented treatments (Fig. S17), suggesting that either PCoA3associated bacteria recycle DOC under replete nutrient conditions, or present increased specificity for substrates produced in $\mathrm{N}^{+}$treatments. Additionally, as larger changes in DOC levels were more precisely predicted by PCoA3 under nutrient addition than in control, bacteria associated with PCoA3 should incorporate or respire autochthonous DOC efficiently. Also, as PCoA3 and 16S abundance simultaneously peaked on day 3, lineages exhibiting high PCoA3 scores should achieve high cell counts, which might explain the efficiency in regulating DOC levels and water transparency (Fig. 4). Our results also showed that reduction of $\mathrm{S}_{350-400}$ and increase of a 350 induced high-PCoA3 bacteria under shading (Fig. 
521 S7), suggesting that high-PCoA3 bacteria are active consumers of HMW, chromophoric

522 DOC, which might be susceptible to photodegradation or have production hampered by

523 photo-inhibition. Brandão et al. (2018) pointed out that during the experiment, autochthonous

524 carbon production increased absorption at wavelengths above $350 \mathrm{~nm}$, adding onto the

525 contribution of freshly produced carbon on PCoA3. Intriguingly, our findings indicate that 526 the Gammaproteobacteria-Flavobacteria (high-PCoA2) growth might have contributed to the 527 PCoA3 pulses by producing HMW aromatic DOC, as high PCoA2 scores preceded pulses in PCoA3 (Fig. S9).

Our results showed that members of the Verrucomicrobiaceae family were enriched at high PCoA3 scores, notably OTUs associated with the genera Prosthecobacter, Haloferula, Brevifollis and Luteolibacter (Fig. 8). Although information concerning the roles of most verrucomicrobial groups in freshwater is still scarce, these genera have been found in different aquatic environments and their adaptive success rely on a broad repertoire of carbon-degrading enzymes (Martinez-Garcia et al., 2012; Zhang et al., 2014; Balmonte et al., 2016). Verrucomicrobiaceae have been previously associated with increases in phytoplankton-derived bioavailable DOM (Landa et al., 2013) and contribute to hydrolysis of complex HMW-polysaccharides (Cardman et al., 2014). Moreover, a metagenomic survey on freshwater Verrucomicrobia revealed an enrichment of Ton transporters genes (CabelloYeves et al., 2017), which code for proteins involved on complex HMW DOM cycling 540 (McCarren et al., 2010). Therefore, our findings suggest that a few closely related lineages consume HMW DOM, most likely of autochthonous origin, indicating an ecologically coherent and exclusive role for Verrucomicrobiaceae in our experiment. This finding contributes to the current knowledge of bacterial taxa involved in the degradation of complex microbial-produced DOM, as data on microbial populations responsible for cycling recalcitrant DOM are still scarce (Zhang et al., 2018). 
547 (a 350 and $\mathrm{S}_{350-400)}$, but also decreased levels of DOC and PAR attenuation. This suggests that 548 high-PCoA3 bacteria likely impacted water transparency, increasing light availability at 549 wavelengths $>400 \mathrm{~nm}$, resulting in a subsequent increased primary productivity and 550 abundance of phototrophs. Likewise, high-PCoA3 bacteria seem to reduce the aromaticity of the DOM pool (SUVA decrease). Thus, high PCoA3-groups like Verrucomicrobiaceae, Chthonomonas (Armatimonadetes), Parafilimonas (Chitinophagaceae), Oceanicoccus (Gammaproteobacteria) and Aquabacterium (Betaproteobacteria) seem to be highly active in recycling DOM. Our results indicate that these bacteria are capable of sensing DOM changes (Fig. S7) and as response, controlling the CDOM fate (quantitatively and qualitatively) by efficiently consuming the accumulated aromatic HMW fraction of the DOM pool, impacting light availability and other community members, specially DOC producers.

\section{Conclusions}

Our results revealed consistent associations between distinct microbial groups and specific changes in the DOM pool over time, suggesting resource partitioning among bacterial groups, as previously reported for the microbial organic matter turnover in the sea (McCarren et al., 2010). We observed a dynamic control of community members on DOM fate, with specialized groups affecting distinct properties of DOM, likely contributing altogether to DOM recycling. The activity of each specialized group was time-dependent: as productivity increased and carbon molecular weight decreased, active consumers of HMW carbon and/or fast-growing strains were gradually replaced by other bacterial groups with affinity for LMW compounds. This exchange occurred concomitantly with a pulse of DOCconsuming, notably Verrucomicrobiaceae, showing preference for chromophoric carbon of autochthonous origin. Some lineages, as Flavobacteriaceae and Gammaproteobacteria might 
have contributed to the production of such complex chromophoric DOM pool. Although the succession pattern described above also occurred in the control (Fig. S9), increasing DOM and nutrient resources enhanced the magnitude of the microbial shifts, likely due to an augmented availability of substrate leading to a higher abundance of the favored groups. Lineages tightly linked to autochthonous carbon production (PCoA1) reflected this trend quantitatively, changing proportionally to the density of primary producers, which imposed a high restrain on background communities. Moreover, the switch between FlavobacteriaGammaproteobacteria and Sporichthyaceae-LD12 groups seems to regulate DOM quality, and distinguished bacterial groups based on molecular weight affinity.

Therefore, our findings claim attention for a verrucomicrobial family (Verrucomicrobiaceae) and other taxa as Chthonomonas and Aquabacterium as short-lived but yet important recyclers of DOM affecting water clarity and re-fueling primary production. These findings expand the basis for future investigations aiming to deep the comprehension of DOM cycling in tropical lakes, which might validate the efficiency of these microbial players as major lineages responsible for CDOM remineralization. Finally, our study confirms that different sources of DOM impact specific bacterial groups differently. More importantly, our findings suggest that taxonomically defined assemblages play definite roles when influencing DOM fate, either by changing specific fractions of the DOM pool or by regulating DOC levels.

\section{Acknowledgements}

This work was supported by the Fundação de Amparo à Pesquisa do Estado de Minas Gerais (FAPEMIG); Conselho Nacional de Desenvolvimento Científico e Tecnológico (CNPq); and Coordenação de Aperfeiçoamento de Pessoal de Nível Superior (CAPES) through the project Carbon Cycling in Lakes (COCLAKE - CAPES Proc. no 88881.030499/2013-01). We would 
596

597

598

599

600

601

602

603

604

605

606

607

608

609

610

611

612

613

614

615

616

617

618

619

620

like to thank Gustavo Turci, Patrícia Ferreira and Ralph Thomé for field support. We also thank Diego Pujoni for his valuable suggestions and Anderson Carmo for the support during DNA sequencing at LBMM-ICB-UFMG.

\section{Figure legends}

Figure 1: Temporal variation of alpha diversity (OTU richness and evenness - Simpson 1/D), 16S copy number, and percentages of bacterioplankton, cyanobacteria and chloroplastassociated reads. Values represent means \pm SE. Red and black colours depict treatments with and without allochthonous DOM addition, respectively. Triangle and circle symbols correspond to treatments with and without nutrient addition, respectively. Solid lines represent shaded treatments and dashed lines indicate full light.

Figure 2: Temporal variation of $\mathrm{a}_{350}, \mathrm{~S}_{275-295}, \mathrm{~S}_{350-400}$, dissolved organic carbon (DOC), SUVA and $K_{d P A R}$. Values represent means \pm SE. Red and black colours depict treatments with and without allochthonous DOM addition, respectively. Triangle and circle symbols correspond to treatments with and without nutrient addition, respectively. Solid lines represent shaded treatments and dashed lines indicate full light.

Figure 3: Temporal variation of PCoA1, 2 and 3. Values represent means \pm SE. Red and black colours depict treatments with and without allochthonous DOM addition, respectively. Triangle and circle symbols correspond to treatments with and without nutrient addition, respectively. Solid lines represent shaded treatments and dashed lines indicate full light.

Figure 4: Diagram illustrating the synchronism between shifts in bacterioplankton community structure and DOM proxies. Detailed statistics are shown on Tables 4 and 5. 
621 Quantitative, quantitative/qualitative and qualitative proxies are represented by ellipses,

622 triangles and rectangles, respectively. Red and green lines represent negative and positive

623

624

625

626

627

628

629

630

631

632

633

634

635

636

637

638

639

640

641

642

643

644

645

associations, respectively. Solid and dashed lines represent significant linearity between a three-day shift $\left(\triangle \mathrm{PCoA}^{0-3}\right.$ and $\left.\Delta \mathrm{DOM}^{0-3}\right)$ and the associated explanatory variable immediately before $\left(\mathrm{PCoA}^{0}\right.$ and $\left.\mathrm{DOM}^{0}\right)$, or after $\left(\mathrm{PCoA}^{3}\right.$ and $\left.\mathrm{DOM}^{3}\right)$ the shift, respectively. Black and yellow stars represent increased fitness of the association under shading and fulllight, respectively.

Figure 5: Ternary plot showing all OTUs of 12 different phyla chosen to represent distinct patterns of occurrence in relation to the three main PCoA axis. Each circle represents one OTU positioned according to the normalized contribution of the indicated PCoA axis (species score) PCoA1 + PCoA2 + PCoA3 = $1(100 \%)$. Colored areas depict the density (Gaussian kernel estimator) of the OTUs distribution. The number between parenthesis indicates the total richness of OTUs for each phylum.

Figure 6: Ternary plot showing all OTUs of 12 different classes chosen to represent distinct patterns of occurrence in relation to the three main PCoA axis. Each circle represents one OTU positioned according to the normalized contribution of the indicated PCoA axis (species score) PCoA1 + PCoA2 + PCoA3 = $1(100 \%)$. Colored areas depict the density (Gaussian kernel estimator) of the OTUs distribution. The number between parenthesis indicates the total richness of OTUs for each class.

Figure 7: Ternary plot showing all OTUs of 16 different families chosen to represent distinct patterns of occurrence in relation to the three main PCoA axis. Each circle represents one OTU positioned according to the normalized contribution of the indicated PCoA axis (species 
score): PCoA1 + PCoA2 + PCoA3 = $1(100 \%)$. Colored areas depict the density (Gaussian

647 kernel estimator) of the OTUs distribution. The number between parenthesis indicates the total richness of OTUs for each family.

Figure 8: Ternary plot showing all OTUs of 16 different genera chosen to represent distinct patterns of occurrence in relation to the three main PCoA axis. Each circle represents one OTU positioned according to the normalized contribution of the indicated PCoA axis (species score): PCoA1 + PCoA2 + PCoA3 = $1(100 \%)$. Colored areas depict the density (Gaussian kernel estimator) of the OTUs distribution. The number between parenthesis indicates the total richness of OTUs for each genus.

\section{References}

657 Amaral, V., Graeber, D., Calliari, D., Alonso, C., 2016. Strong linkages between DOM 658 optical properties and main clades of aquatic bacteria. Limnol. Oceanogr. 61: 906-918.

Amon, R.M.W., Benner, R., 1994. Rapid cycling of high-molecular-weight dissolved organic 660 matter in the ocean. Nature. 369: 549-552.

661 Asmala, E., Haraguchi, L., Carstensen, J., Jakobsen, H., Massicotte, P., 2018. Nutrient availability as major driver of phytoplankton- derived dissolved organic matter transformation in coastal environment. Biogeochemistry. 137: 93-104.

Ávila, M.P., Staehr, P.A., Barbosa, F.A.R., Chartone-Souza, E., Nascimento, A.M.A., 2017. 
Barbosa, L.G, Barbosa, F.A.R., Bicudo, C.E.M., 2012. Inter-annual chemical stratification in Brazilian natural lakes: meromixis and hypolimnetic memory. Acta Limnologica Brasiliensia. 24: $127-139$.

670

Balmonte, J.P., Arnosti, C., Underwood, S., Mckee, B.A., 2016. Riverine bacterial communities reveal environmental disturbance signatures within the Betaproteobacteria and Verrucomicrobia. Front. Microbiol. 7: 1441.

Benner, R. 2002. Chemical composition and reactivity. 59-90. Biogeochemistry of marine dissolved organic matter, Elsevier Science.

Benner, R., Amon, R.M.W., 2015. The size-reactivity continuum of major bioelements in the ocean. Annu. Rev. Mar. Sci. 7: 185-205.

Berggren, M., Laudon, H., Jansson, M., 2009. Aging of allochthonous organic carbon regulates bacterial production in unproductive boreal lakes, Limnol. Oceanogr. 54: 13331342.

680

Berglund, J., Müren, U., Båmstedt, U., Andersson, A., 2007. Efficiency of a phytoplanktonbased and a bacteria-based food web in a pelagic marine system. Limnol. Oceanogr. 52: 121 $-131$.

Bezerra-Neto, J.F., Brighenti, L.S., Pinto-Coelho, R.M., 2010. A new morphometric study of Carioca Lake, Parque Estadual do Rio Doce (PERD), Minas Gerais State, Brazil. Acta Sci Biol Sci. 32: 49-54. and nutrient inputs on the nearshore ecology of a large, oligotrophic lake (Georgian Bay, 
689

690

691

692

693

694

695

696

697

698

699

700

701

702

703

704

705

706

707

708

709

Brandão, L.P.M., Staehr, P.A., Bezerra-Neto, J.F., 2016. Seasonal changes in optical properties of two contrasting tropical freshwater systems. J. Limnol. 75: 18.

Brandão, L.P.M., Brighenti, L.S., Staehr, P.A., Asmala, E., Massicotte, P., Tonetta, D., Barbosa, F.A.R., Pujoni, D., et al., 2018. Distinctive effects of allochthonous and autochthonous organic matter on CDOM spectra in a tropical lake. Biogeosciences. 15: $2931-2943$.

Brighenti, L.S., Staehr, P.A., Gagliardi, L.M., Brandão, L.P.M., Elias, E.C., de Mello, N.A.S.T., Barbosa, F.A.R., Bezerra-Neto, J.F., 2015. Seasonal changes in metabolic rates of two tropical lakes in the Atlantic Forest of Brazil. Ecosystems. 18: 589-604.

Brighenti, L.S., Staehr, P.A., Brandão, L.P.M., Barbosa, F.A.R., Bezerra-Neto, J.F., 2018. Importance of nutrients, organic matter and light availability on epilimnetic metabolic rates in a mesotrophic tropical lake. Freshwater Biol. 63: 1143-1160.

Bunse, C., Bertos-Fortis, M., Sassenhagen, I., Sildever, S., Sjöqvist, C., Godhe, A., Gross, S., Kremp, A., et al., 2016. Spatio-temporal interdependence of bacteria and phytoplankton during a baltic sea spring bloom. Front. Microbiol. 7: 517. doi: 10.3389/fmicb.2016.00517

Cabello-Yeves, P.J., Ghai, R., Mehrshad, M., Picazo, A., Camacho, A., Rodriguez-Valera, F., 2017. Reconstruction of diverse verrucomicrobial genomes from metagenome datasets of freshwater reservoirs. Front. Microbiol. 8: 2131. doi: 10.3389/fmicb.2017.02131

Cardman, Z., Arnosti, C., Durbin, A., Ziervogel, K., Cox, C., Steen, A.D., Teske, A., 2014. Verrucomicrobia are candidates for polysaccharide-degrading bacterioplankton in an Arctic fjord of Svalbard. Appl. Environ. Microbiol. 80: 3749-3756. 
710 Carpenter, S.R., Stanley, E.H., Zanden, M.J.V., 2011. State of the world's freshwater 711 ecosystems: physical, chemical, and biological changes. Annu. Rev. Environ. Resour. 36: 7571299

713 Cory, R.M., Kling, G.W., 2018. Interactions between sunlight and microorganisms influence 714 dissolved organic matter degradation along the aquatic continuum. Limnol. Oceanogr. 715 Letters. 3: 102-116.

716 Cotner, J.B., Biddanda, B.A., 2002. Small players, large role: microbial influence on 717 biogeochemical processes in pelagic aquatic ecosystems. Ecosystems. 5: 105-121.

718 Cui, Y., Jin, L., Ko, S.R., Chun, S.J., Oh, H.S., Lee, C.S., Srivastava, A., Oh, H.M., et al., 719 2017. Periphyton effects on bacterial assemblages and harmful cyanobacterial blooms in a eutrophic freshwater lake: a mesocosm study. Sci. Rep. 7: 7827.

721 De Haan, H., De Boer, T., 1987. Applicability of light absorbance and fluorescence as 722 measures of concentration and molecular size of dissolved organic carbon in humic Laken 723 Tjeukemeer. Water Res. 21: 731-734.

Eckert, E.M., Salcher, M.M., Posch, T., Eugster, B., Pernthaler, J., 2012. Rapid successions 725 affect microbial N-acetyl-glucosamine uptake patterns during a lacustrine spring phytoplankton bloom. Environ. Microbiol. 14: 794-806.

727 Edgar, R.C., Haas, B.J., Clemente, J.C., Quince, C., Knight, R., 2011. UCHIME improves sensitivity and speed of chimera detection. Bioinformatics 27: 2194-2200.

729 Evans, J., Sheneman, L., Foster J.A., 2006. Relaxed Neighbor-Joining: A Fast Distance730 Based Phylogenetic Tree Construction Method. J. Mol. Evol. 62: 785-792. 
731 Farjalla, V.F., Marinho, C.C., Faria, B.M., Amado, A.M., Esteves, F.D.A., Bozelli, R.L., 732 Giroldo, D., 2009. Synergy of fresh and accumulated organic matter to bacterial growth. 733 Microb. Ecol. 57: 657-666.

734 Fonte, E.S., Amado, A.M., Meirelles-Pereira, F., Esteves, F.A., Rosado, A.S., Farjalla, V.F., 735 2013. The combination of different carbon sources enhances bacterial growth efficiency in 736 aquatic ecosystems. Microb. Ecol. 6: 871-878.

737 Fouilland, E., Tolosa, I., Bonnet, D., Bouvier, C., Bouvier, T., Bouvy, M., Got, P., Le Floc’h, 738 E., et al., 2014. Bacterial carbon dependence on freshly produced phytoplankton exudates 739 under different nutrient availability and grazing pressure conditions in coastal marine waters. $740 \quad$ FEMS Microbiol. Ecol. 87: 757-769.

741 Godwin, C.M., Cotner, J.B., 2014. Carbon:phosphorus homeostasis of aquatic bacterial 742 assemblages is mediated by shifts in assemblage composition. Aquat. Microb. Ecol. 73: 245743258.

744 Goldberg, S.J., Nelson, C.E., Viviani, D.A., Shulse, C.N., Church, M.J., 2017. Cascading 745 influence of inorganic nitrogen sources on DOM production, composition, lability and 746 microbial community structure in the open ocean. Environ. Microbiol. 19: 3450-3464.

747 Gomez-Consarnau, L., Lindh, M.V., Gasol, J.M., Pinhassi, J., 2012. Structuring of 748 bacterioplankton communities by specific dissolved organic carbon compounds. Environ. 749 Microbiol. 14: 2361-2378.

750 Guerrero-Feijóo, E., Nieto-Cid, M., Sintes, E., Dobal-Amador, V., Hernando-Morales, V., 751 Álvarez, M., Balagué, V., Varela, M.M., 2017. Optical properties of dissolved organic matter 
752

753

754

755

756

757

758

759

760

761

762

763

764

765

766

767

768

769

770

771

relate to different depth-specific patterns of archaeal and bacterial community structure in the North Atlantic Ocean. FEMS Microbiol. Ecol. 93: 1-14.

Hamilton, N.E., Ferry, M., 2018. "ggtern: Ternary Diagrams Using ggplot2.” Journal of Statistical Software, Code Snippets, 87: 1-17.

Hansen, A.M., Kraus, T.E.C., Pellerin, B.A., Fleck, J.A., Downing, B.D., Bergamaschi, B.A., 2016. Optical properties of dissolved organic matter (DOM): Effects of biological and photolytic degradation. Limnol. Oceanogr. 61: 1015-1032.

Helms, J.R., Stubbins, A., Ritchie, J.D., Minor, E.C., Kieber, D.J., Mopper, K., 2008. Absorption spectral slopes and slope ratios as indicators of molecular weight, source, and photobleaching of chromophoric dissolved organic matter. Limnol. Oceanogr. 53: 955-969.

Jansson, M., Persson, L., De Roos, A.M., Jones, R.I., Tranvik, L.J., 2007. Terrestrial carbon and intraspecific size-variation shape lake ecosystems. Trends in Ecology \& Evolution. 22: $316-22$.

Jones, S.E., Newton, R.J., McMahon, K.D., 2009. Evidence for structuring of bacterial community composition by organic carbon source in temperate lakes. Environ. Microbiol. 11: $2463-72$.

Judd, K.E., Crump, B.C., Kling, G.W., 2006. Variation in dissolved organic matter controls bacterial production and community composition. Ecology. 87: 2068-2079.

Kirk, J.T.O., 1994. Light and photosynthesis in aquatic ecosystems. Cambridge University Press. 
772 Klindworth, A., Pruesse, E., Schweer, T., Peplies, J., Quast, C., Horn, M., Glöckner, F.O.,

773

774

775

776

777

778

779

780

781

782

783

784

785

786

787

2013. Evaluation of general 16S ribosomal RNA gene PCR primers for classical and nextgeneration sequencing-based diversity studies. Nucleic Acids Research. 41(1): e1. doi: 10.1093/nar/gks808

Kritzberg, E.S., Langenheder, S., Lindström, E.S., 2006. Influence of dissolved organic matter source on lake bacterioplankton structure and function - Implications for seasonal dynamics of community composition. FEMS Microbiol. Ecol. 56: 406-417.

Landa, M., Cottrell, M.T., Kirchman, D.L., Blain, S., Obernosterer, I., 2013. Changes in bacterial diversity in response to dissolved organic matter supply in a continuous culture experiment. Aquat. Microb. Ecol. 69: 157-168.

Landa, M., Blain, S., Christaki, U., Monchy, S., Obernosterer, I., 2016. Shifts in bacterial community composition associated with increased carbon cycling in a mosaic of phytoplankton blooms. ISME J. 10: 39-50.

Lane, D.J., 1991. 16S/23S rRNA sequencing (pp. 115-175). In E. Stackebrandt, \& M. Goodfellow (Eds.), Nucleic acid techniques in bacterial systematics, New York, USA: John Wiley and Sons.

Lindeman, R.L., 1942. The trophic-dynamic aspect of ecology. Ecology. 23: 399-418.

Lozupone, C., Knight, R., 2005. UniFrac: a new phylogenetic method for comparing microbial communities. App. Environ. Microbiol. 71: 8228-8235.

Lucas, J., Koester, I., Wichels, A., Niggemann, J., Dittmar, T., Callies, U., Wiltshire, K.H., Gerdts, G., 2016. Short-term dynamics of North Sea bacterioplankton-dissolved organic matter coherence on molecular level. Front. Microbiol. 7: 1-14. 

Jumas-Bilak, E., 2010. Negativicoccus succinicivorans gen. nov., sp. nov., isolated from human clinical samples, emended description of the family Veillonellaceae and description of Negativicutes classis nov., Selenomonadales ord. nov. and Acidaminococcaceae fam. nov. in the bacterial phylum Firmicutes. Int. J Syst. Evol. Microbiol. 60: 1271-1279.

Martinez-Garcia, M., Brazel, D.M., Swan, B.K., Arnosti, C., Chain, P.S., Reitenga, K.G., 800 Xie, G., Poulton, N.J., et al., 2012. Capturing single cell genomes of active polysaccharide degraders: an unexpected contribution of Verrucomicrobia. PLoS One. 7: e35314.

Massicotte, P., Asmala, E., Stedmon, C., Markager, S., 2017. Global distribution of dissolved 803 organic matter along the aquatic continuum: Across rivers, lakes and oceans. Sci. Tot. Environ. 609: 180-191.

McCarren, J., Becker, J.W., Repeta, D.J., Shi, Y., Young, C.R., Malmstrom, R.R., Chisholm, S.W., DeLong, E.F., 2010. Microbial community transcriptomes reveal microbes and metabolic pathways associated with dissolved organic matter turnover in the sea. Proc. Natl. Acad. Sci. 107: 16420-16427.

McKnight, D.M., Andrews, E.D., Spaulding, S.A., Aiken, G.R., 1994. Aquatic fulvic acids in 810 algal-rich antarctic ponds. Limnol. Oceanogr. 39: 1972-1979.

McMurdie, P.J., Holmes, S., 2013. phyloseq: an R package for reproducible interactive analysis and graphics of microbiome census data. PLoS ONE. 8(4): e61217. populations by denaturing gradient gel electrophoresis analysis of polymerase chain reactionamplified genes coding for 16S rRNA. Appl. Environ. Microbiol. 59: 695-700. 
816 Nelson, C.E., Carlson, C.A., 2012. Tracking differential incorporation of dissolved organic

817 carbon types among diverse lineages of Sargasso Sea bacterioplankton. Environ. Microbiol. 14: $1500-1516$

819 Nelson, N.B., Carlson, C.A., Steinberg, D.K., 2004. Production of chromophoric dissolved organic matter by Sargasso Sea microbes. Mar. Chem. 89: 273-287.

821

Orsi, W.D., Smith, J.M., Liu, S., Liu, Z., Sakamoto, C.M., Wilken, S., Poirier, C., Richards, T.A., 2016. Diverse, uncultivated bacteria and archaea underlying the cycling of dissolved protein in the ocean. ISME J. 10: 2158-2173.

Osterholz, H., Singer, G., Wemheuer, B., Daniel, R., Simon, M., Niggemann, J., Dittmar, T., 2016. Deciphering associations between dissolved organic molecules and bacterial communities in a pelagic marine system. ISME J. 10: 1717-1730.

Pankratov, T.A., Tindall, B.J., Liesack, W., Dedysh, S.N., 2007. Mucilaginibacter paludis gen. nov., sp. nov. and Mucilaginibacter gracilis sp. nov., pectin-, xylan and laminarindegrading members of the family Sphingobacteriaceae from acidic Sphagnum peat bog. Int. J. Syst. Evol. Microbiol. 57: 2349-2354.

Paul, A., Dziallas, C., Zwirnmann, E., Gjessing, E.T., Grossart, H.P., 2012. UV irradiation of natural organic matter (NOM): Impact on organic carbon and bacteria. Aquat. Sci. 74: 443454.

Paulson, J.N., Stine, O.C., Bravo, H.C., Pop, M., 2013. Differential abundance analysis for microbial marker-gene surveys. Nature Methods. 10: 1200-1202. implications. Nat. Rev. Microbiol. 3: 537-547. 
838

839

840

841

842

843

844

845

846

847

848

849

850

851

852

853

854

855

856

857

Quast, C., Pruesse, E., Yilmaz, P., Gerken, J., Schweer, T., Yarza, P., Peplies, J., Glöckner, F.O., 2013. The SILVA ribosomal RNA Gene Database Project: improved data processing and web-based tools. Nucleic Acids Research. 41(Database issue): D590-D596. https: //doi.org/10.1093/nar/gks1219

Reis, M.P., Barbosa, F.A.R., Chartone-Souza, E., Nascimento, A.M.A., 2013. The prokaryotic community of a historically mining-impacted tropical stream sediment is as diverse as that from a pristine stream sediment. Extremophiles. 17: 301-309.

Reis, P.C.J., Martinelli, L.A., Barbosa, F.A.R., 2016. Basal carbon sources and planktonic food web in a tropical lake: an isotopic approach. Mar. Freshwater Res. 68: 429-441.

Rochelle-Newall, E., Delille, B., Frankignoulle, M., Gattuso, J.P., Jacquet, S., Riebesell, U., Terbruggen, A., Zondervan, I., et al., 2004. Chromophoric dissolved organic matter in experimental mesocosms maintained under different pCO2 levels. Mar. Ecol. Prog. Ser. 272: $25-31$.

Roiha, T., Peura, S., Cusson, M., Rautio, M., 2016. Allochthonous carbon is a major regulator to bacterial growth and community composition in subarctic freshwaters. Sci. Rep. 6: $1-12$.

Sanders, R.W., Cooke, S.L., Fischer, J.M., Fey, S.B., Heinze, A.W., Jeffrey, W.H., A.L., Macaluso, Moellert, R.E., et al., 2015. Shifts in microbial food web structure and productivity after additions of naturally occurring dissolved organic matter: Results from large-scale lacustrine mesocosms. Limnol. Oceanogr. 60: 2130-2144. 
Sarmento, H., Morana, C., Gasol, J.M., 2016. Bacterioplankton niche partitioning in the use of phytoplankton-derived dissolved organic carbon: quantity is more important than quality. ISME J. 10: 2582-2592.

Schloss, P.D., Westcott, S.L., Ryabin, T., Hall, J.R., Hartmann, M., Hollister, E.B., Lesniewski, R.A., Oakley, B.B., et al., 2009. Introducing mothur: Open-source, platformindependent, community-supported software for describing and comparing microbial communities. Appl. Environ. Microbiol. 75: 7537-7541.

Šimek, K., Kasalický, V., Jezbera, J., Jezberová, J., Hejzlar, J., Hahn, M.W., 2010. Broad habitat range of the phylogenetically narrow R-BT065 cluster, representing a core group of the betaproteobacterial genus limnohabitans. Appl. Environ. Microbiol. 76: 631-639.

Smith, H.J., Dieser, M., McKnight, D.M., SanClements, M.D., Foreman, C.M., 2018. Relationship between dissolved organic matter quality and microbial community composition across polar glacial environments. FEMS Microbiol. Ecol. 94: 1-10.

Starr, E.P., Shi, S., Blazewicz, S.J., Probst, A.J., Herman, D.J., Firestone, M.K., Banfield, J.F., 2018. Stable isotope informed genome-resolved metagenomics reveals that Saccharibacteria utilize microbially-processed plant-derived carbon. Microbiome 6: 1-12.

Sterner, R.W., Elser, J.J., 2002. Ecological Stoichiometry: The biology of elements from molecules to the Biosphere. Princeton University Press, Princeton.

Tonetta, D., Staehr, P.A., Obrador, B., Brandão, L.P.M., Brighenti, L.S., Petrucio, M.M., Barbosa, F.A.R., Bezerra-Neto, J.F., 2018. Effects of nutrients and organic matter inputs in the gases $\mathrm{CO}_{2}$ and $\mathrm{O}_{2}$ : A mesocosm study in a tropical lake. Limnologica. 69: 1-9. 
879 Weishaar, J.L., Aiken, G.R., Bergamaschi, B.A., Fram, M.S., Fujii, R., Mopper, K., 2003. 880 Evaluation of specific ultraviolet absorbance as an indicator of the chemical composition and 881 reactivity of dissolved organic carbon. Environ. Sci. Technol. 37: 4702-4708.

882 Wickham, H., 2016. ggplot2: elegant graphics for data analysis. Springer New York.

883 Wiegel, J., Tanner, R., Rainey, F.A., 2006. An introduction to the family Clostridiaceae. In 884 The Prokaryotes: a handbook on the biology of bacteria, 3rd edn, vol. 4, pp. 654-678. Edited by M. Dworkin, S. Falkow, E. Rosenberg, K. H. Schleifer \& E. Stackebrandt. Springer: New 886 York.

Wu, X., Wu, L., Liu, Y., Zhang, P., Li, Q., Zhou, J., Hess, N.J., Hazen, T.C., et al., 2018. Microbial interactions with dissolved organic matter drive carbon dynamics and community 889 succession. Front. Microbiol. 9: 1-12.

890

Zhang, C., Dang, H., Azam, F., Benner, R., Legendre, L., Passow, U., Polimene, L., 891 Robinson, C., et al., 2018. Evolving paradigms in biological carbon cycling in the ocean. 892 National Science Review. 5: 481-499.

893

Zhang, J., Zhang, X., Liu, Y., Xie, S., Liu, Y., 2014. Bacterioplankton communities in a high894 altitude freshwater wetland. Ann. Microbiol. 64: 1405-1411. exopolysaccharide in natural marine microbial communities. PLoS One. 10: 1-16. 

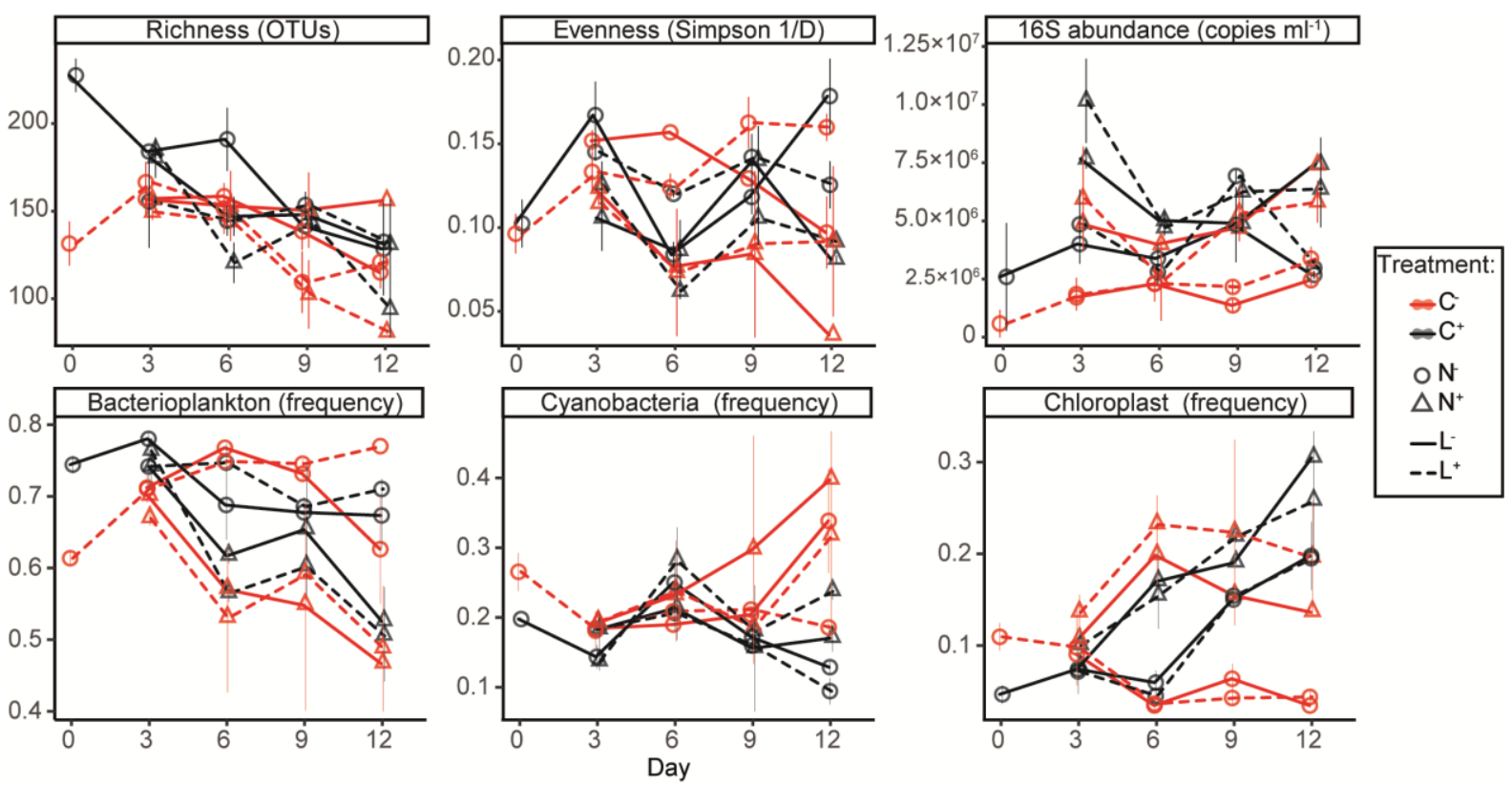

$900 \quad$ Figure 1.

901

902
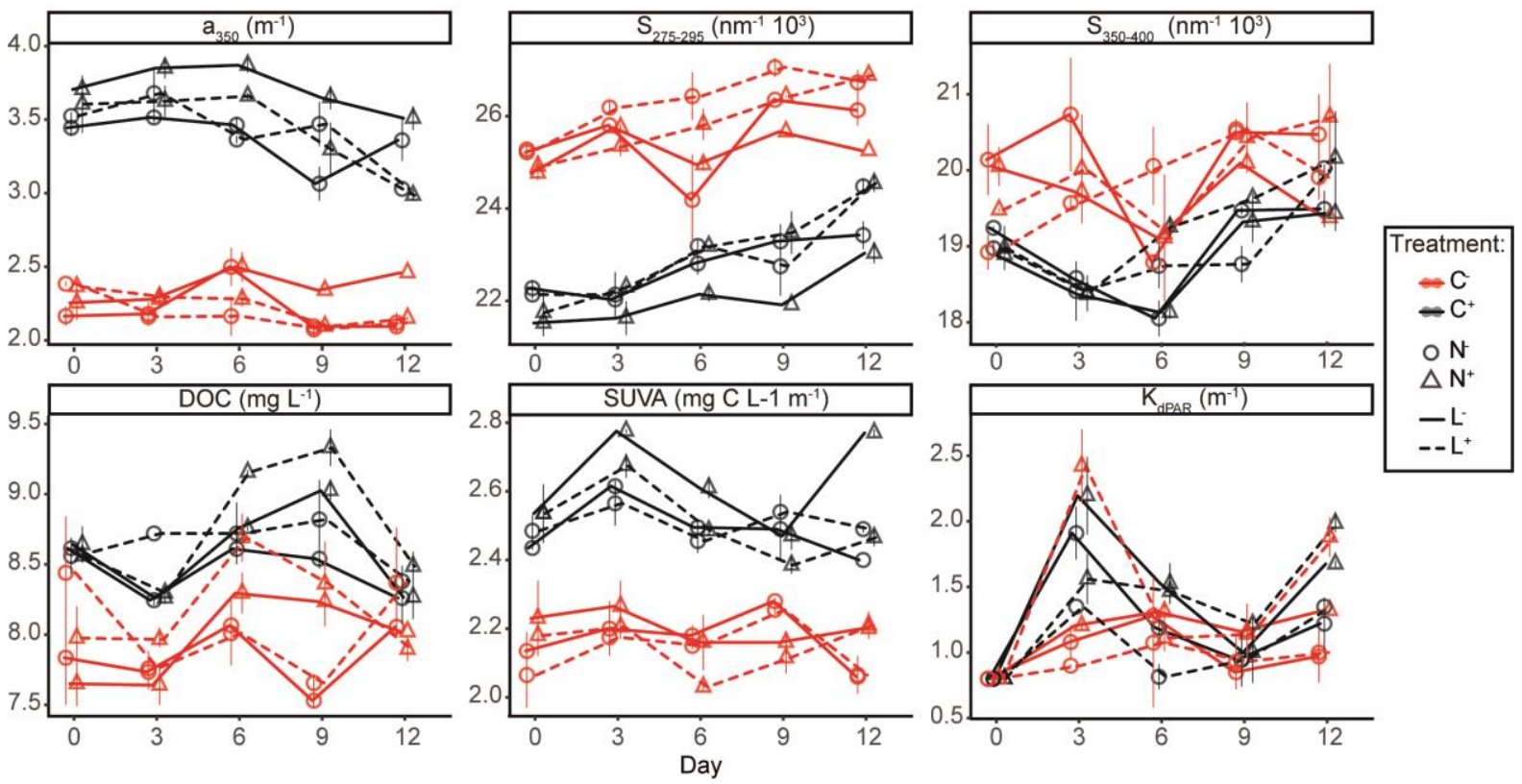

903

Figure 2. 

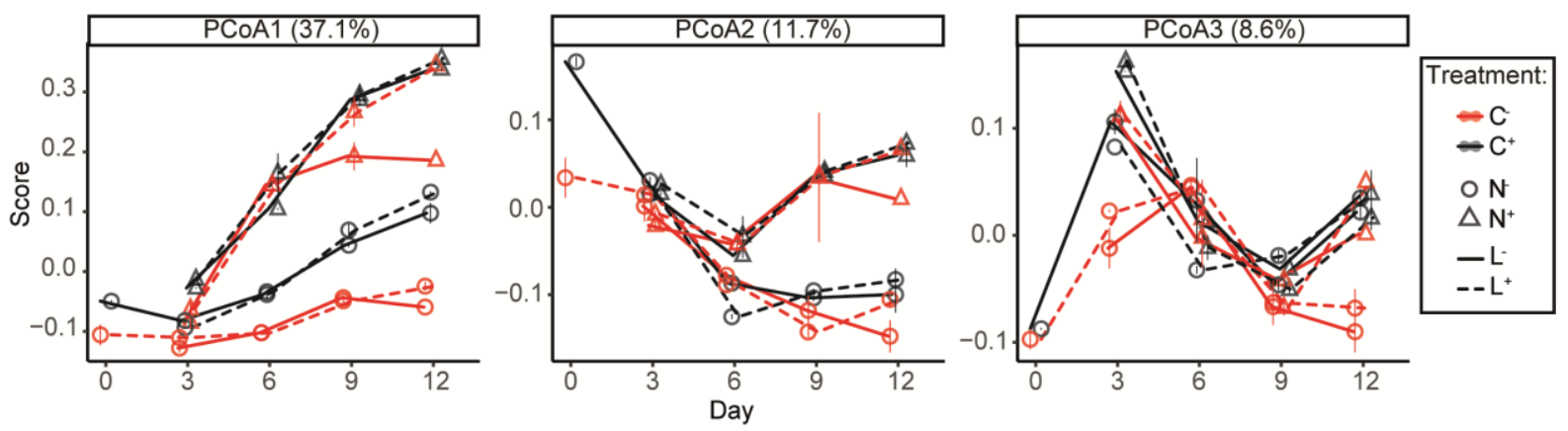

906 Figure 3.

907

\section{BCS-DOM synchrony:}

$$
\text { A -...>B }
$$

Changes in variable $A$ influence following variable $B$ levels:

Positively Negatively
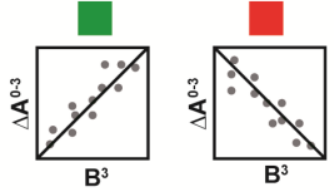

$$
A \longrightarrow B
$$

Variable A levels influence following changes in variable $B$

Positively

Negatively
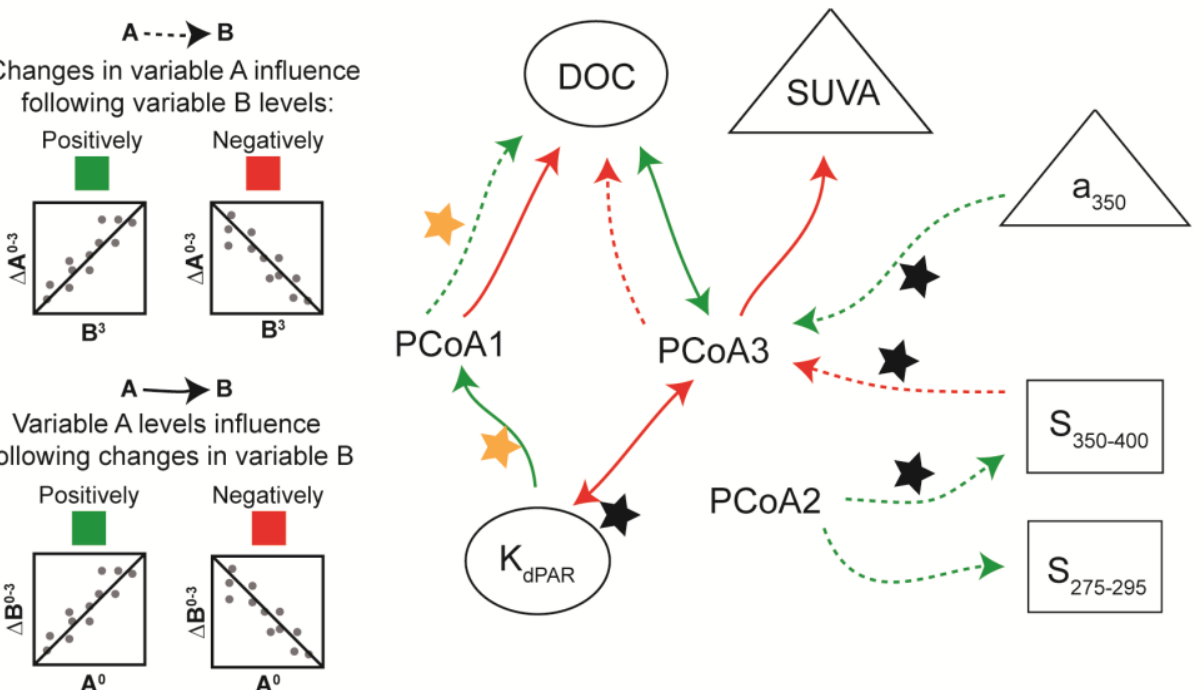

Influence of light:

Association more

predictable under shading

Association more

predictable under full-light

Type of DOM proxy:

$\bigcirc$ quantitative qualitative/

908

Figure 4. 


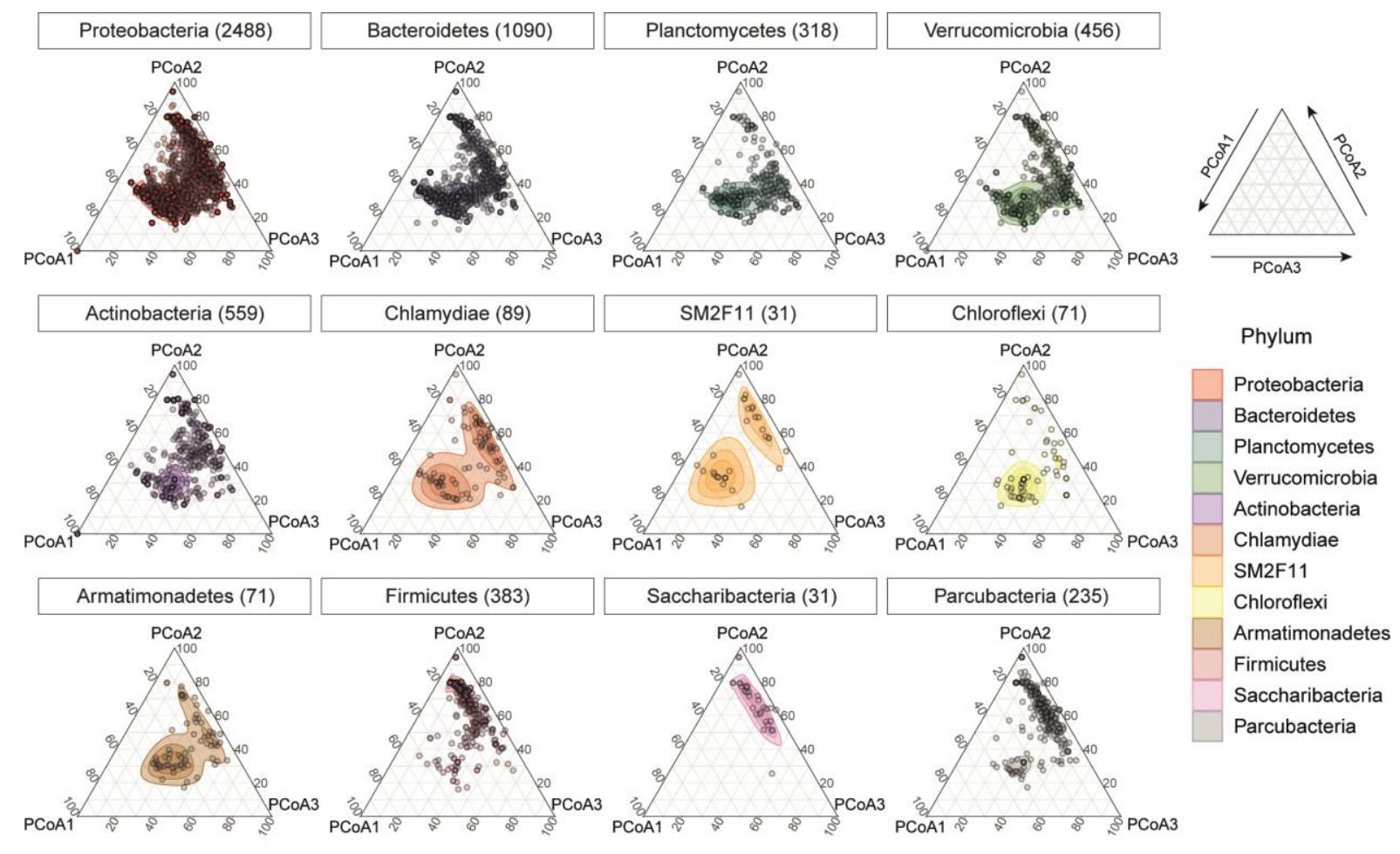

912 Figure 5.

913
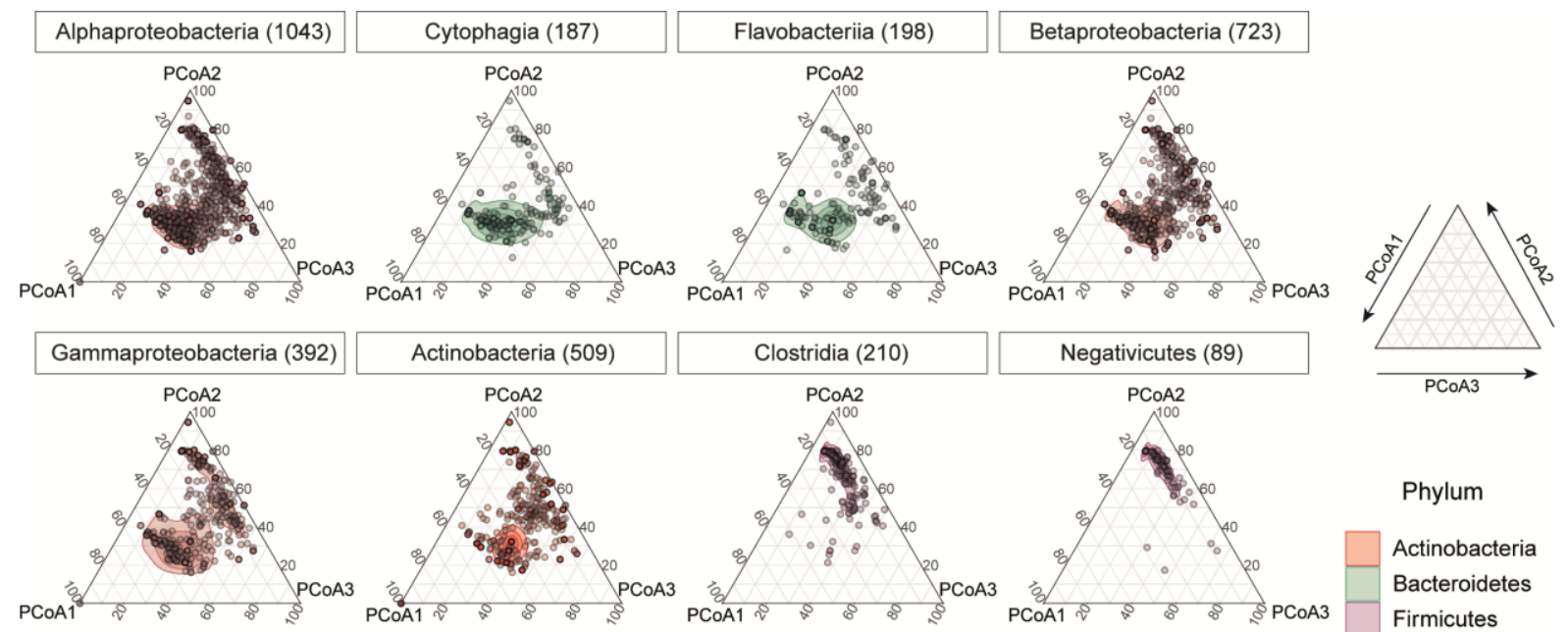

Phylum

Actinobacteria

Bacteroidetes

Firmicutes

Planctomycetes

Proteobacteria

Verrucomicrobia
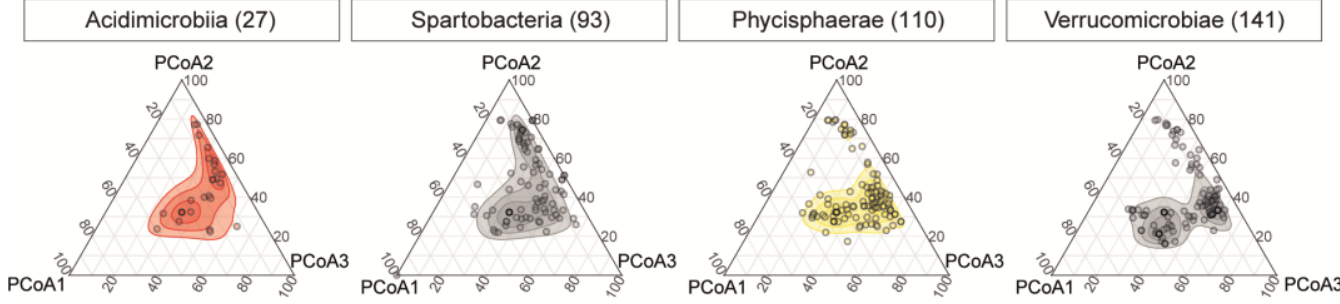

915 Figure 6. 


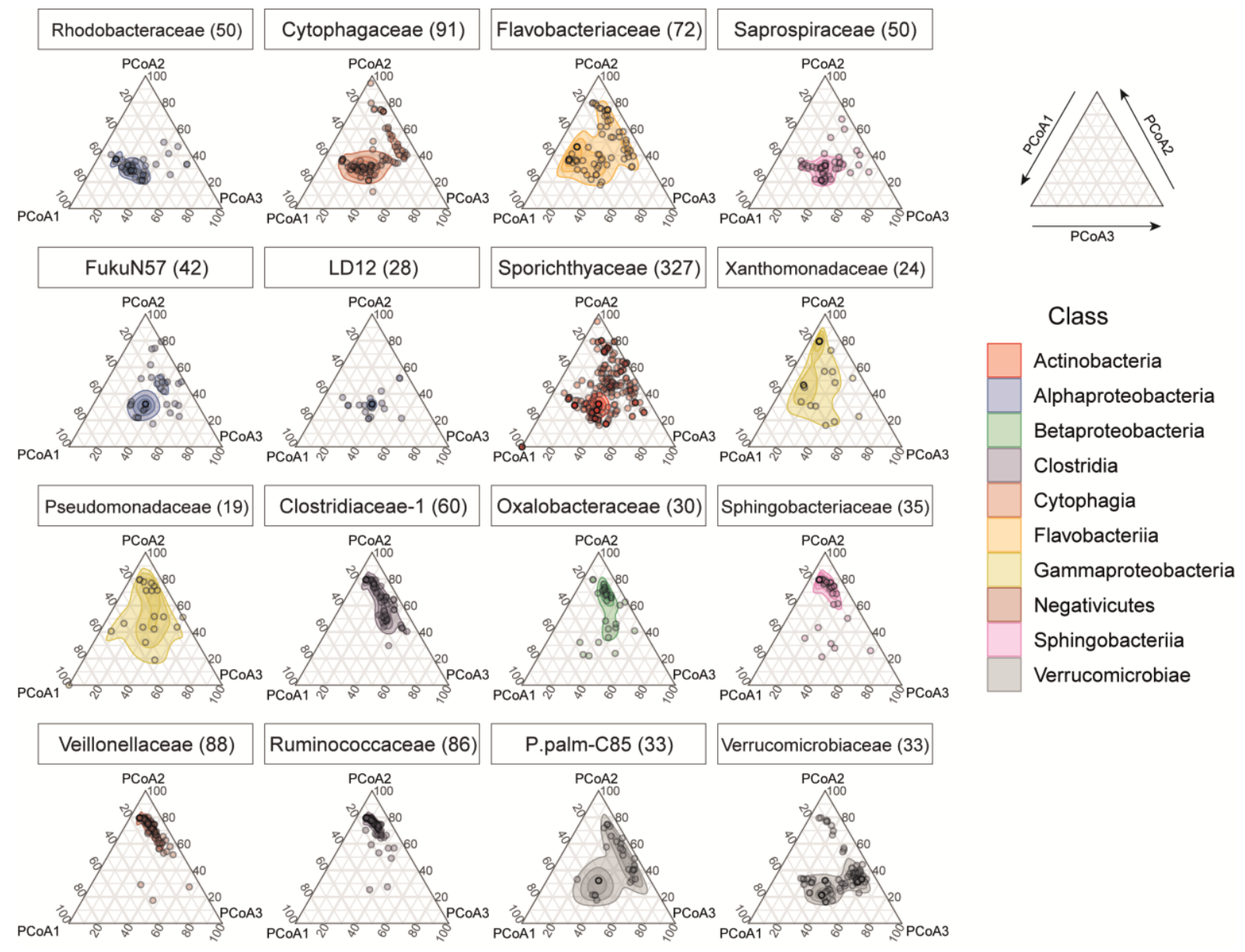

$918 \quad$ Figure 7.

919 

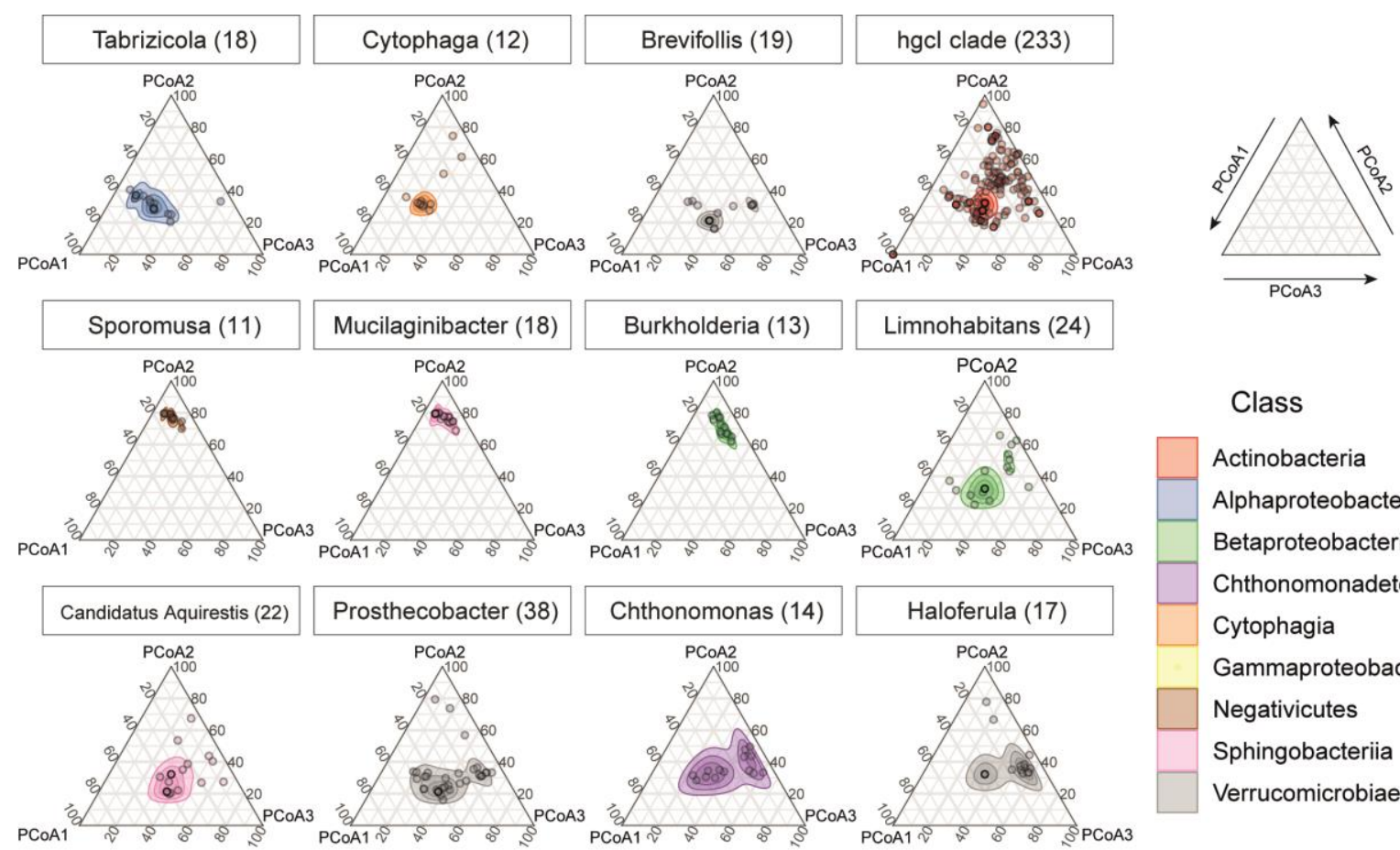

\section{Class}

Actinobacteria

Alphaproteobacteria

Betaproteobacteria

Chthonomonadetes

Cytophagia

Gammaproteobacteria

Negativicutes

Sphingobacteriia

Verrucomicrobiae

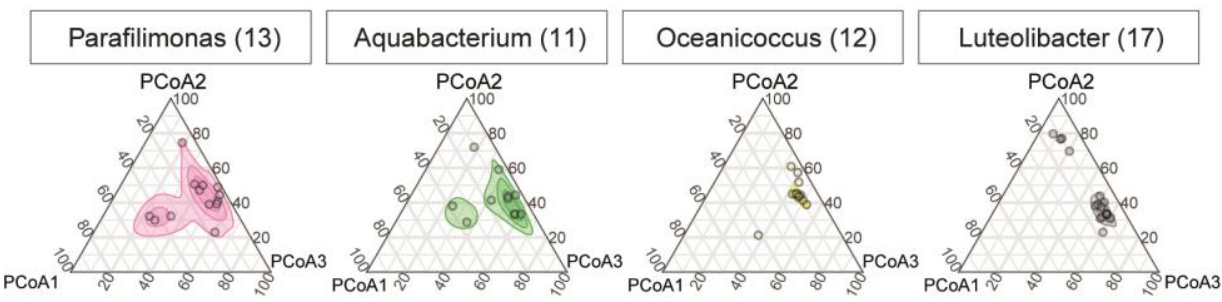

921 Figure 8. 
Table 1: Multiple linear regressions results, displaying the effect of the manipulations as mean overall changes and changes per day (indicated by the interaction of the manipulation with time) on $16 \mathrm{~S}$ abundance, bacterioplankton richness and evenness and the relative frequency of bacterioplankton, cyanobacteria and chloroplasts.

\begin{tabular}{|c|c|c|c|c|c|c|}
\hline & & & Allochthonous DOM addition & Nutrient addition & Shading & $\begin{array}{l}\text { Combined } \\
\text { addition }\end{array}$ \\
\hline & $\operatorname{adj} R^{2}$ & $\begin{array}{l}\text { change per day } \\
\text { (control) }\end{array}$ & $\begin{array}{l}\text { overall change/ } \\
\text { daily change }\end{array}$ & $\begin{array}{l}\text { overall change/ } \\
\text { daily change }\end{array}$ & $\begin{array}{l}\text { overall } \\
\text { change }\end{array}$ & overall change \\
\hline 16S abundance & 0.48 & - & $+331.0 \%[* * *] /-19.3 \%[]$. & $+291.1 \%[* *] /-$ & - & - \\
\hline Richness & 0.55 & $-1.9 \%[*]$ & $+25.5 \%[* *] /-$ & - & $+15.1 \%[]$. & - \\
\hline Evenness & 0.22 & - & - & $-/-3.1 \%[]$. & - & - \\
\hline Bacterioplankton & 0.56 & - & - & $-/-2.9 \%[* * *]$ & - & - \\
\hline Cyanobacteria & 0.19 & - & $-/-5.8 \%[*]$ & $-/+5.3 \%[*]$ & - & - \\
\hline Chloroplasts & 0.72 & $-5.0 \%[]$. & $-86.0 \%[* *] /+18.0 \%[* * * *]$ & $+65.3 \%[*] /+8.4 \%[* *]$ & - & $-53.4 \%[*]$ \\
\hline
\end{tabular}

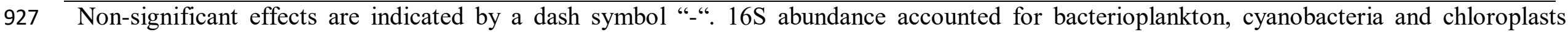

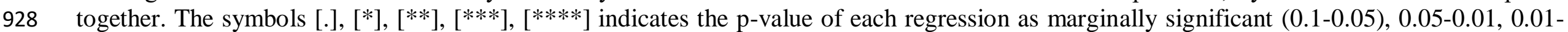
$92910 \mathrm{E}^{-3}, 10 \mathrm{E}^{-3}-10 \mathrm{E}^{-5},<10 \mathrm{E}^{-5}$, respectively. 
Table 2: Multiple linear regressions results, displaying the effect of the manipulations as mean overall changes and changes per day (indicated by the interaction of the manipulation with time) on dissolved organic carbon (DOC), aromaticity (SUVA), absorbance at $350 \mathrm{~nm}$ (a350) and the spectral slopes between 275-295nm ( $\left.\mathrm{S}_{275-295}\right)$ and 350-400nm $\left(\mathrm{S}_{350-400}\right)$.

\begin{tabular}{lllllll}
\hline & & Allochthonous DOM addition & Nutrient addition & Shading & \multicolumn{1}{c}{$\begin{array}{l}\text { Nutrient addition } \\
\text { shaded }\end{array}$} \\
\hline & adj $\mathbf{R}^{2}$ & $\begin{array}{l}\text { change per day } \\
\text { (control) }\end{array}$ & $\begin{array}{l}\text { overall change/ } \\
\text { daily change }\end{array}$ & $\begin{array}{l}\text { overall change/ } \\
\text { daily change }\end{array}$ & $\begin{array}{l}\text { overall change/ daily } \\
\text { overall change }\end{array}$ \\
\hline DOC & 0.45 & - & $+8.7 \%[* * *] /-$ & - & - & - \\
SUVA & 0.79 & - & $+17.2 \%[* * * *] /-$ & $+3.9 \%[] /-$. & - & - \\
$\mathbf{a}_{350}$ & 0.94 & $-0.96 \%\left[{ }^{* *}\right]$ & $+56.5 \%[* * * *] /-1.1 \%[* *]$ & $+9.1 \%[*] /-$ & $-7.7 \%[*] /-$ & $+9.1 \%[* *]$ \\
$\mathbf{S}_{275-295}$ & 0.91 & $+0.2 \%[]$. & $-13.3 \%\left[\left[^{* * * *}\right] /+0.2 \%[]\right.$. & $-2.2 \%[*] /-$ & $-/-0.3 \%[* *]$ & - \\
$\mathbf{S}_{350-400}$ & 0.42 & - & $-6.5 \%\left[\left[^{* *}\right] /-\right.$ & - & $+3.7 \%[*] /-0.4 \%[*]$ & $-2.6 \%[]$. \\
\hline
\end{tabular}

934 Non-significant effects are indicated by a dash symbol "-“. The symbols [.], [*], [**], [***], [****] indicates the p-value of each regression as 935 marginally significant $(0.1-0.05), 0.05-0.01,0.01-10 \mathrm{E}^{-3}, 10 \mathrm{E}^{-3}-10 \mathrm{E}^{-5},<10 \mathrm{E}^{-5}$, respectively. 
Table 3: Multiple linear regressions results, displaying the effect of the manipulations as mean overall changes and changes per day (indicated by the interaction of the manipulation with time) on the main principal coordinates PCoA1, PCoA2 and PCoA3.

\begin{tabular}{|c|c|c|c|c|c|c|c|}
\hline & & & & $\begin{array}{l}\text { Allochthonous } \\
\text { addition }\end{array}$ & Nutrient addition & Shading & $\begin{array}{l}\text { Combined } \\
\text { addition }\end{array}$ \\
\hline & $\begin{array}{l}\% \text { of community } \\
\text { variance }\end{array}$ & adj $R^{2}$ & $\begin{array}{l}\text { change per day } \\
\text { (control) }\end{array}$ & $\begin{array}{l}\text { overall change/ } \\
\text { daily change }\end{array}$ & $\begin{array}{l}\text { overall change/ } \\
\text { daily change }\end{array}$ & $\begin{array}{l}\text { daily } \\
\text { change }\end{array}$ & $\begin{array}{l}\text { overall } \\
\text { change }\end{array}$ \\
\hline PCOA1 & $37.1 \%$ & 0.93 & $+10.5 \%\left[^{*}\right]$ & $+67.4 \%[] /.+11.7 \%\left[{ }^{* *}\right]$ & $-/+42.4 \%[* * * *]$ & - & $-83.9 \%[* *]$ \\
\hline PCOA2 & $11.7 \%$ & 0.68 & $-7.3 \%[* * * *]$ & - & $-41.0 \%\left[{ }^{* * *}\right] /+9.2 \%\left[{ }^{* * * *}\right]$ & $-2.5 \%[]$. & - \\
\hline PCOA3 & $8.6 \%$ & 0.25 & - & - & $+75.3 \%[* * *] /-6.8 \%\left[{ }^{* *}\right]$ & - & - \\
\hline
\end{tabular}

940 The percentage of variance explained by each axis is also displayed. Non-significant effects are indicated by a dash symbol "-“. The symbols [.],

$941[*],[* *],[* * *],[* * * *]$ indicates the $\mathrm{p}$-value of each regression as marginally significant $(0.1-0.05), 0.05-0.01,0.01-10 \mathrm{E}^{-3}, 10 \mathrm{E}^{-3}-10 \mathrm{E}^{-5},<10 \mathrm{E}^{-5}$, 942 respectively. 
Table 4: Effect of BCS on DOM. Results of the of linear regressions tested between DOM proxies and BCS, which was evaluated as changes in scores of the three main PCoA's axes within three-day intervals. The results show significant associations $\left(p\right.$-value $\left.<0.05, R^{2}>0.2\right)$ about changes in BCS that determine DOM fate $\left(\triangle \mathrm{PCoA}^{0-3} \sim \mathrm{DOM}^{3}\right)$ and changes in DOM pool that are determined by a previous community $\left(\triangle \mathrm{DOM}^{0-3} \sim \mathrm{PCoA}^{0}\right)$.

Changes in BCS determine DOM

BCS determines changes in DOM

\begin{tabular}{|c|c|c|c|c|c|c|c|c|c|c|c|}
\hline \multicolumn{12}{|c|}{ All treatments + control } \\
\hline$\triangle P C o A^{0-3}(y)$ & $\operatorname{DOM}^{3}(x)$ & intercept & coef. & $R^{2}$ & $p$-value & $\Delta \mathrm{DOM}^{0-3}(\mathrm{y})$ & $\operatorname{PCoA}^{0}(x)$ & intercept & coef. & $R^{2}$ & p-value \\
\hline \multirow[t]{2}{*}{ PCoA1 } & DOC & -0.570 & 0.077 & 0.273 & $1.65 \mathrm{E}-04$ & DOC & PCoA3 & -0.022 & 3.783 & 0.288 & $1.02 \mathrm{E}-04$ \\
\hline & & & & & & SUVA & PCOA3 & -0.003 & -0.845 & 0.217 & 0.001 \\
\hline \multicolumn{12}{|c|}{ Only treatments } \\
\hline$\triangle P C o A^{0-3}(y)$ & $\operatorname{DOM}^{3}(x)$ & intercept & coef. & $R^{2}$ & p-value & $\Delta \mathrm{DOM}^{0-3}(\mathrm{y})$ & $\mathrm{PCoA}^{0}(x)$ & intercept & coef. & $R^{2}$ & $p$-value \\
\hline PCOA2 & $S_{275-295}$ & -0.546 & 0.022 & 0.213 & 0.007 & DOC & PCoA1 & 0.164 & -2.757 & 0.442 & $2.47 \mathrm{E}-05$ \\
\hline PCOA2 & $S_{350-400}$ & -1.152 & 0.059 & 0.385 & $1.17 \mathrm{E}-04$ & DOC & PCOA3 & -0.114 & 5.290 & 0.657 & 1.07E-08 \\
\hline PCOA3 & DOC & 1.073 & -0.128 & 0.244 & 0.003 & SUVA & PCOA3 & 0.026 & -1.345 & 0.589 & $3.02 \mathrm{E}-07$ \\
\hline РCOA3 & $\mathrm{K}_{\mathrm{dPAR}}$ & -0.208 & 0.139 & 0.219 & 0.006 & & & & & & \\
\hline
\end{tabular}


Table 5: Effect of DOM on BCS. Results of the of linear regressions tested between DOM proxies and BCS, which was evaluated as changes in scores of the three main PCoA's axes within three-day intervals. The results show significant associations $\left(p\right.$-value $\left.<0.05, R^{2}>0.2\right)$ about changes in DOM that determine BCS fate $\left(\triangle \mathrm{DOM}^{0-3} \sim \mathrm{PCoA}^{3}\right)$ and changes in BCS that are determined by a previous $\mathrm{DOM}$ pool $\left(\triangle \mathrm{PCo} \mathrm{A}^{0-3} \sim\right.$ $\mathrm{DOM}^{0}$ ).

\section{Changes in DOM determine BCS}

\section{All treatments + control}

\section{Only treatments}

\begin{tabular}{|c|c|c|c|c|c|c|c|c|c|c|c|}
\hline$\triangle D^{\prime} O M^{0-3}(y)$ & $\operatorname{PCoA}^{3}(x)$ & intercept & coef. & $R^{2}$ & $p$-value & $\triangle P C o A^{0-3}(y)$ & $\operatorname{DOM}^{0}(x)$ & intercept & coef. & $R^{2}$ & $p$-value \\
\hline \multirow[t]{3}{*}{$S_{350-400}$} & PCoA3 & 0.276 & -10.168 & 0.286 & 0.001 & PCoA1 & $\mathrm{K}_{\mathrm{dPAR}}$ & 0.002 & 0.071 & 0.251 & 0.003 \\
\hline & & & & & & PCOA3 & DOC & -0.932 & 0.106 & 0.207 & 0.008 \\
\hline & & & & & & PCOA3 & $K_{\text {dPAR }}$ & 0.146 & -0.125 & 0.372 & $2.08 \mathrm{E}-04$ \\
\hline
\end{tabular}

\section{DOM determines changes in BCS}

\begin{tabular}{llllll}
$\Delta \mathrm{PCOA}^{0-3}(\mathrm{y})$ & $\mathrm{DOM}^{\mathbf{0}}(\mathrm{x})$ & intercept & coef. & $\boldsymbol{R}^{2}$ & $\boldsymbol{p}$-value \\
\hline PCOA1 & $\mathrm{K}_{\mathrm{dPAR}}$ & -0.035 & 0.089 & 0.344 & $1.82 \mathrm{E}-05$ \\
PCOA3 & $\mathrm{K}_{\mathrm{dPAR}}$ & 0.120 & -0.111 & 0.299 & $8.45 \mathrm{E}-05$
\end{tabular}

